\title{
LOS ACUERDOS EXTRAJUDICIALES DESDE LA VISIÓN PRIVATISTA DEL DERECHO CONCURSAL
}

[Extrajudicial Agreements from the Privatistic Approach of Bankruptcy Laws]

\author{
Juan Luis Goldenberg Serrano* \\ Pontificia Universidad Católica de Chile
}

\begin{abstract}
RESUMEN
El interés en el estudio de los acuerdos extrajudiciales puede parecer menor en comparación con el análisis de las figuras estrictamente concursales. No obstante, justificados por un giro hacia orientaciones privatistas, el derecho comparado ha prestado especial atención a estas herramientas a la espera de que el acuerdo privado logre rescatar a los deudores de manera más eficiente y rápida que las respuestas judiciales. Pero se reconocen las dificultades que implica la aplicación irrestricta de un marco contractual a las si-
\end{abstract}

\begin{abstract}
It may seem less interesting to study extrajudicial agreements rather than analysing matters strictly dealing with bankruptcy. However, justified by a twist into privatistic tendencies, comparative law has given special importance to these tools while waiting that private agreements are able to restore debtors more efficiently and quickly than judicial responses. However, it also recognizes the difficulties of an unrestricted application of a contractual framework to situations of patrimonial crisis, which are interwo-
\end{abstract}

RECIBIDo el 4 de marzo y aceptado el 2 de junio de 2014

* Doctor en derecho por la Universidad de Salamanca; profesor de derecho civil en la Facultad de Derecho de la Pontificia Universidad Católica de Chile. Dirección postal: Av. Libertador Bernardo O’Higgins $N^{\circ} 340$, Santiago, Chile. Correo electrónico: jgoldenb@uc.cl. Este trabajo se inscribe en el proyecto Fondecyt de Iniciación de Investigación N¹1121139 ("Fundamentos dogmáticos de la visión privatista del derecho concursal"). 
tuaciones de crisis patrimonial, imbricada por el conflicto de intereses y la pluralidad de partes, hasta modificar algunos de sus pilares tradicionales. El punto también debe ser analizado en el contexto de la Ley $\mathrm{N}^{\circ} 20.720$ que ha incidido con mayor fuerza en la utilización de la autonomía privada como principio orientador de nuestro derecho concursal.

Palabras clave

Derecho concursal - Privatización del concurso - Acuerdos extrajudiciales. ven by conflicts of interest and the number of parties, until changing some of its traditional foundations. This also should be analysed considering the context of Act No. 20.720, which strongly affected the use of private autonomy as a principle to orientate our bankruptcy laws.

\section{KeYWords}

Bankruptcy laws - Privatization of the tender - Extrajudicial agreements.

\section{INTRODUCCIÓN}

Históricamente, las visiones publicistas del derecho concursal han presentado graves objeciones a la sola posibilidad del acuerdo extrajudicial, sea porque se trata de un mecanismo que impide la reacción sancionatoria por parte de las autoridades, sea porque sólo se concentra en el interés tutelar del crédito, desconociendo otros factores (extracrediticios) que podían ser igualmente relevantes para la vigilancia de la estabilidad económica ${ }^{1}$. Al contrario, la consagración de un modelo privatista - que centra su mirada en el poder concedido a los particulares en el diseño de la solución al dilema que implica la insolvencia del deudor ${ }^{2}$ - decantará en la posibilidad de que sean éstos quienes puedan llegar a un acuerdo lícito que resuelva la incidencia de la crisis en sus pretensiones de cobro. Esta construcción advierte la identificación entre los intereses privados, fundados en la pretensión de pago de cada acreedor, con el interés general previsto en el derecho concursal, en el que se articulan herramientas para lograr la maximización de las posibilidades de satisfacción de los créditos mediante la configuración de un foro común de solución ${ }^{3}$.

\footnotetext{
${ }^{1}$ Respecto a la evolución de los convenios extrajudiciales en nuestro sistema jurídico: Goldenberg Serrano, Juan Luis, Los acuerdos extrajudiciales en la legislación concursal, en Revista de Derecho de la Empresa, 20 (2009), pp. 73-100.

${ }^{2}$ Goldenberg Serrano, Juan Luis, Bases para la privatización del derecho concursal, en Revista Chilena de Derecho Privado, 20 (2013), pp. 9-49.

${ }^{3}$ Véase especialmente: JACKson, Thomas H., The Logic and Limits of Bankruprcy Law (Cambridge, Harvard University Press, 1986), passim; y Tirado Martí, Ignacio, Reflexiones sobre el concepto de "interés concursal" (Ideas para la construcción de una
} 
Desde una perspectiva económica, la principal orientación de la regulación privatista de la crisis patrimonial reposa en la eficiencia de la solución alcanzada, medida en razón del aumento de las posibilidades de cobro de los acreedores ${ }^{4}$. Así, debe comprenderse que un mecanismo basado únicamente en el acuerdo inter partes, ajeno a un modelo propiamente concursal, sólo tiene sentido en cuanto sea posible articularlo bajo la lógica de una "operación de mercado"s, en que oferta y demanda se encuentren en un supuesto abstracto de competencia perfecta ${ }^{6}$. Entonces, se advierte que un reconocimiento a la técnica contractual, como fórmula jurídica en que se materializa el acuerdo, debe estar constituida como un medio idóneo para lograr la anhelada eficiencia, alejándose del paradigma tradicional que había visto en la intervención judicial una mejor respuesta a la crisis, aun cuando ésta estuviese igualmente enfocada en la idea de la tutela del crédito ${ }^{7}$.

Siguiendo las explicaciones de Fernández del Pozo: "El famoso Teorema de Coase nos permite concluir que siempre que los costes de transacción de la renegociación extrajudicial de la deuda sean inferiores a los mayores costes relativos estimados, directos e indirectos, de la solución concursal, cualquier acreedor racional preferiría eludir la entrada en el concurso judicial"'. Pero a ello hay que agregar, como anticipa Guglielmucci, que si bien la solución privatista parece justificarse en la reducción del elevado costo de la respuesta

teoría sobre la finalidad del concurso de acreedores), en Anuario de Derecho Civil, 62 (2009) 3, p. 1.059.

${ }^{4}$ Núñez Ojeda, Raúl - Carrasco Delgado, Nicolás - Ortiz Rojo, Francisco, Visión crítica desde el análisis económico del derecho al sistema de verificación de créditos y realización de activos en la ley de quiebras chilena, en Ius et Praxis, 18 (2012) 1, p. 271.

${ }^{5}$ Posner, Richard, Economic Analysis of Law (Boston - Toronto, Little Brown, 1977), pp. 11-12.

${ }^{6}$ COASE, Ronald, The Problem of Social Cost, en Journal of Law and Economics, 3 (1960), p. 18, señala: "las regulaciones generales que deben aplicarse a una amplia variedad de casos serán ejecutadas en algunos casos en los que son claramente inapropiadas. Por estas consideraciones, se sigue que la regulación estatal directa no necesariamente conllevará mejores resultados que dejando el problema a ser resuelto por el mercado o la empresa" (traducción del autor).

${ }^{7}$ Véase: SATTA, Salvatore, Instituciones de derecho de quiebras (traducción y notas de derecho Argentino por Rodolfo O. Fontanarrosa, Buenos Aires, Ediciones Jurídicas Europa-América, 1951), p. 6; y RIPERT, Georges, Tratado elemental de derecho comercial (traducción de Felipe de Solá Cañizares, Buenos Aires, Tipográfica Editora Argentina, 1954), IV, p. 219.

${ }^{8}$ Fernández del Pozo, Luis, El régimen jurídico preconcursal de los "cuerdos de refinanciación" (d.ad. $4^{a}$ LC). Propuesta de reforma legislativa (Madrid, Colegio de Registradores de la Propiedad y Mercantiles de España, 2010), pp. 41-42. 
judicial (pública), la formulación del acuerdo no está ciertamente exenta de la existencia de costos?.

En el presente trabajo pretendemos describir los problemas derivados de una formulación contractual del acuerdo extrajudicial y constatar cómo la autocomposición puede resultar de difícil configuración en un gran elenco de situaciones de insolvencia, dado que, a medida que aumenta la complejidad de la composición del pasivo del deudor, los costos de transacción involucrados para alcanzar un acuerdo extrajudicial eficiente se incrementarán hasta el punto de comprometer su viabilidad. Lo anterior, como marco conceptual para examinar las soluciones previstas en el derecho comparado para resolver estos aspectos, y para revisar la lógica de la nueva regulación de esta clase de acuerdos contemplada en la Ley $\mathrm{N}^{\circ}$ 20.720: De reorganización y liquidación de empresas y personas (= LRLEP.).

\section{Problemas de la construcción Contractual DEL ACUERDO EXTRAJUDICIAL}

En el marco de un conflicto entre acreedores y deudor derivado de la insolvencia de este último, el recurso a la negociación se dificulta especialmente en atención a dos elementos fundantes de la lógica contractual: las reglas generales aplicables para la formación del consentimiento y el efecto relativo del acuerdo. En un contexto de pluralidad de actores e intereses, veremos cómo cada uno de ellos debe ser resuelto a efectos de conseguir una respuesta eficiente, que, como hemos indicado, constituye un objetivo rector del derecho concursal moderno.

\section{Problemas derivados de la ausencia de reglas especiales para la formación del acuerdo extrajudicial.}

Cabe anotar que las reglas generales de formación del consentimiento pretenden configurar un mecanismo para asegurar la correspondencia de voluntades entre las partes involucradas ${ }^{10}$, sin que el sistema común contenga paliativos específicos para facilitar el acuerdo en caso que se evidencien dificultades derivadas, por ejemplo, de la multiplicidad de interesados o de la heterogeneidad de sus posiciones jurídicas y económicas ${ }^{11}$. En razón de ello,

${ }^{9}$ Guglielmucci, Lino, Diritto fallimentare (Torino, Giappichelli, 2012), p. 13.

${ }^{10}$ Ferrari, Franco, La formación del contrato, en Galgano, Francesco (coordinador), Atlas de derecho privado comparado (traducción de Juan Antonio Fernández Campos y Rafael Verdera Server, Madrid, Fundación Cultural del Notariado, 2010), p. 136.

${ }^{11}$ Una crítica efectuada al teorema de Coase es que éste supondría una negociación sólo entre dos agentes, pero desconocería la posibilidad de existir más de un interesado 
la configuración de cualquier fórmula de solución de corte contractual debe enfrentar un problema muchas veces ajeno a las corrientes publicistas del derecho concursal, como es el conflicto entre acreedores ${ }^{12}$. En los modelos clásicos, en los que la dirección del concurso era entregada a órganos públicos, la posibilidad de conflicto era bastante menor, en atención a que la respuesta concursal no era entregada directamente a los acreedores, por lo que sus intereses personales quedaban subordinados a los intereses generales protegidos por la decisión heterónoma ${ }^{13}$. Asimismo, la ritualidad y el control judicial de los acuerdos admisibles en un esquema publicista, reflejados generalmente en el tratamiento normativo de los convenios, también implicaba un mecanismo tutelar a los acreedores minoritarios (disidentes o no concurrentes) de modo que difícilmente la votación mayoritaria podría destinarse a un deterioro injustificado de sus posibilidades de cobro ${ }^{14}$. Pero el énfasis en la solución contractual debe hacer frente a estos posibles conflictos, analizando con mayor prolijidad las motivaciones que se esconden tras el ejercicio de la autonomía privada por parte de los acreedores, especialmente en los casos en los que no se establece una organización especial (particularmente colegial) para conformar una voluntad común, y en la que se pretende un continuo decaimiento de la intervención judicial o administrativa como fórmula de control del acuerdo.

Por su parte, la ausencia de un reconocimiento especial al iter negocial puede dar lugar al comportamiento estratégico del deudor, como consecuencia del hecho que no se establezcan deberes específicos de información, posibilitando un problema de selección adversa derivada de dicha asimetría informativa ${ }^{15}$. Pero aun en caso contrario, en que pueden entenderse ínsitos en todo proceso de negociación ciertos y contundentes deberes de buena fe y de información ${ }^{16}$, el sistema general del contrato no logra asegurar

en un juego infinito de pretensiones conexas. En estos casos, como los que usualmente supone el escenario concursal, será difícil ofrecer ejemplos en que realmente no existan costos de transacción. Véase: Usher, Dan, The Coase Theorem is Tautological, Incoherent or Wrong, en Economic Letters, 61 (1998), p. 10.

${ }^{12}$ Véase especialmente: D'ATTORE, Giacomo, Il conflitto d'interesi fra creditori nei concordati, en Giurisprudenza Commerciale, 36 (2009) 6, passim.

${ }^{13}$ Aunque trata del punto específicamente en materia de homologación de convenios, véase: GutiérRez GiLSAnZ, Andrés, Tutela de los acreedores frente al convenio concursal: Oposición, nulidad y declaración de incumplimiento (Getafe, La Ley, 2009), pp. 25-47.

${ }^{14}$ D'Attore, Giacomo, cit. (n. 12), pp. 392-393.

${ }^{15}$ Para una comprensión específica de los problemas de selección adversa en escenarios de ignorancia, véase: LópeZ-CuÑat, Javier Mateo, Adverse Selection Under Ignorance, en Economic Theory, 16 (2000) 2, pp. 379-399.

${ }^{16}$ Román Rodríguez, Juan Pablo, Instituciones de derecho concursal (Santiago, 
íntegramente la comprensión del contenido contractual propuesto a sus destinatarios, limitando especialmente la eficacia del error, como vicio del consentimiento, a sus magnitudes más relevantes ${ }^{17}$. El punto resulta crucial, en especial en casos en los que los planes de saneamiento son financiera o estructuralmente complejos, o en que al menos algunos de los acreedores que deban concurrir al acuerdo no se encuentren preparados para comprender su contenido.

\section{Problemas derivados del efecto relativo del contrato.}

Situados ahora en la idea del efecto relativo del contrato, debe hacerse notar la posibilidad de que los acreedores se comporten estratégicamente a fin de obtener para sí mayores ventajas, con el menor grado de sacrificio posible. Esta cuestión es usualmente atendida por la doctrina bajo la idea de que el propio ordenamiento jurídico puede permitir el denominado "holdout" de los acreedores ${ }^{18}$, sea amenazando con escapar de un proceso de negociación para dar inicio a una solución judicial (el "acreedor obstructor"), sea comportándose a modo de "acreedor parásito", adquiriendo para sí los beneficios del acuerdo alcanzado con otros (en especial, los que emanan del aumento de sus posibilidades de cobro), sin mediar sacrificios por su parte.

Estos extremos han permitido a la doctrina comparada constatar un problema de negociación básico de esta suerte de acuerdos a partir del "dilema del prisionero": la falta de cooperación, incluso frente a una salida financieramente favorable, puede dejar en mejor posición a los acreedores que deciden no participar, pero el número de "acreedores parásitos" no puede elevarse hasta el punto de hacer inviable la solución propuesta ${ }^{19}$. No obstante,

Abeledo Perrot - Thomson Reuters, 2011), pp. 462-465; y Beltrán SÁnCHEz, Emilio - García Cruces, José Antonio, Acuerdos de refinanciación, en Beltrán SánChez, Emilio - García Cruces, José Antonio (directores), Enciclopedia de derecho concursal (Cizur Menor, Thomson Reuters - Aranzadi, 2012), p. 164.

${ }^{17}$ DE LA MAZA GAZMURI, Íñigo, Los límites del deber precontractual de información (Cizur Menor, Civitas - Thomson Reuters, 2010), p. 277-282.

${ }^{18}$ Para una definición general de "holdout" como cualquier circunstancia en la que una entidad no puede actuar unilateralmente, esto es, realizar una acción sin el consentimiento de alguna otra entidad o entidades, véase: Epstein, Richard A., Holdouts, Externalities and the Single Owner: One More Salute to Ronald Coase, en The Journal of Law and Economics, 36 (1993) 1, p. 559. A su vez, para la comprensión de los problemas que ocasiona un supuesto de "holdout", en razón de la distribución inequitativa de excedente disponible por el intercambio, los costos de demora en la negociación y los fallos en perfeccionar intercambios eficientes, véase: Collins, Sean - IsAAC, R. Mark, Holdout: Existence, Information, and Contingent Contracting, en The Journal of Law and Economics, 55 (2012) 4, p. 794.

${ }^{19}$ Roe, Mark J., The Voting Prohibition in Bond Workouts, en The Yale Law Journal, 97 (1987) 2, pp. 236-237. 
Schwartz agrega que el citado dilema lleva a la conclusión que los involucrados deberían racionalmente constatar los beneficios de la coordinación, de lo que resultaría que la oferta obtendría una fuerza económicamente coercitiva ${ }^{20}$. Pero, como el mismo autor apunta, ello será así en caso que la propuesta sea asumida por los acreedores como más ventajosa que la que supone su no participación en el acuerdo, aun cuando éste no sea finalmente alcanzado ${ }^{21}$.

A su vez, un contexto de insolvencia acentuará las dificultades de un negocio de efectos relativos si se toma en consideración la difusa coordinación del acuerdo extrajudicial con el sistema concursal previsto por parte del ordenamiento jurídico ${ }^{22}$. Estos problemas surgen en el momento en que la regulación establece preferencias hacia una respuesta concursal, sin perjuicio del hecho que reconozca, expresa o tácitamente, la admisibilidad del acuerdo al margen de ella. Un sistema jurídico podrá estar particularmente interesado en que se dé pronto inicio al concurso a efectos de evitar el progresivo deterioro patrimonial del deudor ${ }^{23}$, de manera de aminorar el riesgo de la "cáscara vacía" 24 . Medidas regulatorias que por cierto juegan en contra de la oportunidad para proponer un acuerdo extrajudicial, especialmente si se trata de un mecanismo cuyo proceso de negociación no se encuentra amparado por parte del ordenamiento jurídico, y, aún más, si dicho proceso no involucra a la unanimidad de los acreedores. Así, el deudor se encontrará en una posición negociadora deficiente ante la eventualidad de la calificación del concurso por la infracción del deber de instar al mismo, al tiempo que la conservación de la posibilidad de los acreedores (negociadores o no) para solicitar su apertura o, incluso, para iniciar ejecuciones singulares, puede constituir una amenaza constante para poner término intempestivo al proceso de negociación. Así también, el problema de coordinación podrá poner en riesgo la eficacia del acuerdo alcanzado ante la eventual apertura del concurso, especialmente por la persistencia de amplios medios de la tutela de los acreedores no concurrentes, y, por tanto, ajenos a la fuerza vinculante del contrato, mediante el ejercicio de las acciones revocatorias concursales.

Por su parte, hace un buen tiempo que la doctrina ha aclarado que el

${ }^{20}$ SCHWARTz, Alan, Bankruptcy Workouts and Debt Contracts, en Journal of Law and Economics, 36 (1993) 1, pp. 596-597.

${ }^{21}$ Schwartz, Alan, cit. (n. 20), pp. 597-599.

${ }^{22}$ Pulgar Esquerra, Juana, Preconcursalidad y Acuerdos de Refinanciación (Madrid, La Ley, 2012), p. 64.

${ }^{23}$ Goldenberg Serrano, Juan Luis, El problema temporal en el inicio de los procedimientos concursales, en Ius et Praxis, 18 (2012) 1, pp. 315-346.

${ }^{24}$ Núñez Ojeda, Raúl - Carrasco Delgado, Nicolás, La quiebra sin bienes. Una aproximación desde el análisis económico del derecho, en Ius et praxis, 17 (2011) 1, pp. 139-176. 
efecto relativo del contrato no supone una completa inoponibilidad del mismo ante terceros ${ }^{25}$. Sólo supone que las obligaciones que de él resultan no pueden ser impuestas a quienes no han manifestado una voluntad favorable, pero no implica que deben despreciarse sus efectos reflejos, sea para beneficiar o perjudicar la posición de terceros. Esta cuestión tiene particular importancia toda vez que existe una innegable vinculación entre los acreedores, concurrentes o no al acuerdo, en consideración a la idéntica "garantía" ofrecida por el patrimonio del deudor común. Para resolver este punto, la solución concursal, construida sobre la base de la colectividad, supondrá un mecanismo de coordinación tasado, construido por medio de una serie de reglas y salvaguardas para lidiar con el conflicto de intereses inmanente entre los acreedores. Ellos pasarán desde la configuración de órganos deliberativos, del otorgamiento o la privación del derecho a voto, de la configuración del principio mayoritario, $\mathrm{y}$, eventualmente, de la revisión judicial del contenido del acuerdo. Nada de ello se ofrece en una mecánica íntegramente contractual. De ello resulta que los efectos positivos del acuerdo se extenderán, a modo de externalidades, a entes ajenos a la negociación por el hecho de que cualquier aporte o sacrificio efectuado por los acreedores concurrentes se comportarán económicamente como "bienes públicos" (esto es, las mejoras patrimoniales se resolverán como bienes no rivales ni excluyentes), permitiendo un comportamiento parasitario por parte de un grupo de acreedores, y generando una ineficiencia económica en la lógica de la distribución de recursos ${ }^{26}$.

\section{LOS AJUSTES AL MODELO EXTRAJUDICIAL EN LA EXPERIENCIA COMPARADA}

En el contexto del derecho comparado, no hay lugar a dudas que los ojos han estado puestos en el modelo instaurado por el Capítulo $11^{\circ}$ del Bankruptcy Code estadounidense (USC. 11) ${ }^{27}$. Sin perjuicio que éste se enmarca en un modelo judicial de composición, tiene importancia para el presente discurso en razón de lo que la práctica ha venido en denominar

${ }^{25}$ Por todos, López Santa María, Jorge, Los contratos. Parte general (5a edición actualizada por Fabián Elorriaga de Bonis, Santiago, Abeledo Perrot - LegalPublishing, 2010), p. 308.

${ }^{26}$ Sobre las consecuencias económicas del tratamiento de los bienes públicos o de acceso abierto, véase: MÉNDEZ GonZÁlEz, Fernando, Fundamentación económica del derecho de propiedad privada e ingeniería jurídica del intercambio personal (Cizur Menor, Civitas - Thomson Reuters, 2011), pp. 39-42.

${ }^{27}$ Para un estudio más amplio del capítulo $11^{\circ}$, véase: WARREN, Elizabeth, Chapter 11: Reorganizing American Businesses (Nueva York, Wolters Kluwer, Aspen Publishers, 2008), passim. 
"pre-packaged agreements". Estos surgen en el marco de la necesidad de conciliar los acuerdos extrajudiciales ("private workouts"), con el estatuto reglamentario de los acuerdos judiciales celebrados en el marco del citado Capítulo $11^{28}$. La técnica pasa por llevar a cabo una negociación privada hasta obtener la aceptación de los acreedores al plan a ser presentado al tribunal, rigiéndose esta forma de votación inorgánica por normas íntegramente extraconcursales (sección 1125, g USC. 11). Consiguiendo lo anterior, el deudor presenta, conjuntamente con la solicitud de apertura del concurso, el plan de reorganización ya aprobado, votación que será aceptada por el tribunal a menos que encuentre razones para desestimar el proceso previo. Ello supone la revisión judicial tanto del contenido del acuerdo, que debe conciliarse con la normativa aplicable del Capítulo 11, como de la forma de obtención de los votos de los acreedores, haciendo énfasis en la información proporcionada ("disclosure") por el deudor a tales efectos ${ }^{29}$. Esta articulación permite conceder mayor velocidad, flexibilidad y reducción de costos a las partes ${ }^{30}$, al tiempo que desarticula la posibilidad del acreedor parásito, puesto que la "homologación" judicial tendrá por consecuencia la ruptura del efecto relativo ${ }^{31}$.

Dado que un análisis más acabado de la figura pasa por una comprensión mayor de una legislación que en muchos aspectos se nos presenta como ajena, preferimos dar cuenta del punto sólo a efectos de constatar el modo en el que otros ordenamientos han utilizado este modelo para proponer formas de protección al acuerdo extrajudicial y fomentar su utilización práctica. El derecho comparado no sólo ha avanzado en reconocer la posibilidad de la autocomposición, sino que también ha configurado instrumentos específicos para sortear muchos de los problemas antes anotados por la aplicación estricta del modelo contractual. Estas formas de acuerdo son usualmente estudiadas a la luz de los resguardos concedidos por los ordenamientos jurídicos, a modo de "escudos protectores" ${ }^{2}$, poniendo especial énfasis en

${ }^{28}$ Para una comprensión de las ventajas de los “pre-packaged agreements”, véase: Arias Varona, Francisco Javier, Los acuerdos de refinanciación en el contexto comparado, en Arias Varona, Francisco Javier (director), Conservación de empresas en crisis. Estudios jurídicos y económicos (Madrid, La Ley, 2013), pp. 38-41.

${ }^{29}$ McCormack, Gerard, Corporate Rescue Law. An Anglo-American Perspective (Cheltenham, Edward Elgar Publishing, 2008), pp. 103-107.

${ }^{30}$ Para un análisis de costos de esta clase de acuerdos, véase: Betker, Brian L., An Empirical Examination of Prepacked Bankruptcy, en Financial Management, 24 (1995) 1, pp. 3-4.

${ }^{31}$ McCormack, Gerard, cit. (n. 29), pp. 15 y 103.

${ }^{32}$ Para un estudio crítico a la luz del tratamiento general de los "escudos protectores" de los acuerdos extrajudiciales, véase: Pulgar EsQuerra, Juana, Protección de las refinanciaciones de deuda frente a solicitudes de concurso necesario: sobreseimiento en 
su coordinación con las soluciones concursales. Sin embargo, nos interesa su revisión desde la perspectiva de la alteración del paradigma contractual, pasando por el fortalecimiento del proceso de negociación y por la mayor o menor ruptura de sus efectos relativos.

3. La ruptura de la formulación puramente contractual del acuerdo extrajudicial.

a) El modelo español: los acuerdos de refinanciación. En su texto original, la Ley $\mathrm{N}^{\circ} 22 / 2003$, concursal (= LC.) desestimó cualquier regulación de herramientas contractuales para la superación de la crisis. Sin desestimar expresamente la validez de un acuerdo extrajudicial, pretendió crear incentivos para que los agentes económicos prefiriesen una solución concursal, especialmente por medio de la incorporación de la figura de la "insolvencia inminente" como presupuesto para el inicio de un concurso voluntario (artículo 5.2 LC.) ${ }^{33}$; y el denominado “convenio anticipado”, como fórmula de solución concordataria prevista en la fase común del concurso ${ }^{34}$.

Pero esta visión fue superada por la cruda crisis económica experimentada por España a poco entrar a regir la nueva regulación. Los acuerdos de refinanciación, recogidos inicialmente en la Disposición adicional cuarta LC. (introducida por el Real Decreto-ley $\mathrm{N}^{\circ} 3 / 2009$ ), supusieron la instauración de un modelo completamente inorgánico de los acuerdos preconcursales, bajo una primera esperanza de hacer partícipes a los acreedores en el salvamento de las empresas. El reconocimiento inicial de esta figura sólo protegía el citado acuerdo del ejercicio de las acciones de reintegración (artículo 71 LC.), amparado en el juicio positivo por parte de un experto independiente designado por el registrador mercantil, sobre la suficiencia de la información proporcionada por el deudor, el carácter razonable y realizable del plan de viabilidad y la proporcionalidad de las garantías conforme a las condiciones normales de mercado en el momento de su suscripción. Punto focal de la protección es, en consecuencia, la articulación del acuerdo de refinanciación

los pagos y comunicación ex articulo 5.3 LC en el marco del RDL 3/2009, en Revista de Derecho Concursaly Paraconcursal, 11 (2009), pp. 51-53.

${ }^{33}$ Para un planteamiento general sobre la insolvencia inminente, véase BELTRÁN SÁNCHEZ, Emilio, Insolvencia, insolvencia inminente e insolvencia cualificada, en SARCINA, Antonio- GARCía-CruCEs, José Antonio (directores), Il trattamento giuridico della crisi d'impresa. Profili di diritto concorsuale italiano e spagnolo a confronto (Bari, Cacucci, 2008), pp. 51-71. Asimismo, sobre la relación entre el supuesto de insolvencia inminente y la posibilidad de un acuerdo preventivo extrajudicial, véase PULGar EsQUerra, Juana, Preconcursalidad, cit. (n. 22), pp. 59-63.

${ }^{34}$ Véase: De la Cuesta Rute, José María, El convenio concursal. Comentarios a los artículos 98 a 141 de la Ley concursal (Cizur Menor, Thomson-Aranzadi, 2004), pp. 68-107. 
en el marco de un plan de viabilidad, de manera que la solución negocial queda irrefragablemente unida a una finalidad conservatoria de la empresa, $\mathrm{y}$, por supuesto, a un interés de prevención del concurso ${ }^{35}$, mediante la renegociación u otorgamiento de nuevos créditos.

En este contexto, el instrumento inicialmente previsto por el Real Decreto-ley $\mathrm{N}^{\circ} 3 / 2009$ mantenía una vertiente contractual ${ }^{36}$, aunque, para los fines de protección de las acciones de reintegración, establecía el requisito adicional del necesario consentimiento de acreedores representantes de tres quintos del pasivo, sin establecer mecanismos orgánicos ni procedimientos específicos para alcanzar el acuerdo. Este elemento coincide con la previsión general de la legislación concursal española que, incluso en caso de concurso, expresa una decadencia del modelo orgánico para la conformación de voluntades colectivas ${ }^{37}$, al tiempo que pretende asegurar la ausencia de "manipulaciones interesadas" aumentando considerablemente la entidad necesaria del pasivo para alcanzar la inmunidad revocatoria ${ }^{38}$. De este modo, si bien el acuerdo de refinanciación no lograba extender el contenido de sus disposiciones a terceros no suscriptores, si conseguía alcanzar efectos respecto a éstos privándolos del ejercicio de las citadas acciones de reintegración, por medio de la eliminación del elemento de perjuicio envuelto en ellas una vez cumplidos los requisitos taxativamente indicados en la Disposición adicional cuarta LC. ${ }^{39}$.

La participación del experto no puede apreciarse desde una perspectiva orgánica procesal, especialmente si se toma en cuenta que no nos encontramos aún en el contexto de un procedimiento judicial, sino sólo de un requisito específico para lograr la protección del acuerdo en un eventual supuesto de concurso. Asimismo, el informe del citado experto tampoco puede ser

${ }^{35}$ Encino Alonso-Muñumer, María, El plan de viabilidad en el ámbito de los acuerdos de refinanciación, en Conservación de empresas en crisis. Estudios jurídicos y económicos (Madrid, La Ley, 2013), p. 105.

${ }^{36}$ Para una alusión expresa sobre la incidencia de la autonomía privada en la configuración de estos acuerdos, véase Pulgar EsQuerra, Juana, Acuerdos de refinanciación y fresh money, en Revista de Derecho Concursal y Paraconcursal, 15 (2011), p. 48; y García-Cruces González, José Antonio - López SÁnchez, Javier, La reforma de la Ley concursal. Una primera lectura del Real Decreto-ley 3, 2009 (Cizur Menor, Aranzadi Thomson Reuters, 2009), p. 20.

${ }^{37}$ Álvarez San José, María, El poder de decisión de los acreedores en el concurso (Cizur Menor, Thomson-Civitas, 2005), pp. 287-299.

${ }^{38}$ García-Cruces González, José Antonio - López Sánchez, Javier, cit. (n. 36), p. 29.

${ }^{39}$ Ello, a modo de presunción iuris et de iure sobre la ausencia de perjuicio, tal y como expresa López Sánchez, Javier, El proceso concursal (Cizur Menor, Thomson Reuters Aranzadi, 2012), p. 47. 
asumido como una asistencia técnica a las partes, especialmente en razón a su intervención posterior al perfeccionamiento del acuerdo ${ }^{40}$, a pesar de que indirectamente se imponga el deber del deudor de disminuir las asimetrías informativas sobre la idea del necesario pronunciamiento sobre la suficiencia de la información provista en el marco del acuerdo. Esta formulación, que parece escasa desde la apreciación de las dificultades de la negociación, se justifica en que el tratamiento de los acuerdos extraconcursales en España ha respondido a la necesidad de dar mayor participación a los acreedores profesionales en la solución global de la crisis económica ${ }^{41}$, y particularmente como reacción a la jurisprudencia que había atacado estas formas de acuerdo por medio del ejercicio de las acciones de reintegración y la eventual subordinación legal de los créditos basada en la mala fe del acreedor ${ }^{42}$.

En atención a las insuficiencias del modelo inicial, el sistema español fue profundamente modificado por medio de la Ley 38/2011, aunque siempre manteniendo la pretensión de conservar la base contractual de esta especie de acuerdos extrajudiciales ${ }^{43}$. En primer término, y especialmente a fin de evitar el problema del "holdout", consagró una fórmula para proteger la fase de negociación del acuerdo de refinanciación, en el sentido de suspender la obligación de solicitar la declaración del propio concurso del deudor (artículo 5 bis LC.) e impedir su apertura a solicitud de los acreedores (artículo 15.3 LC.), una vez que el deudor ponga en conocimiento del juzgado competente que ha iniciado negociaciones para alcanzar dicho acuerdo ${ }^{44}$. En consecuencia, la ley implantará una fórmula paralela al pactum de non petendo, pero no configurada ya sobre la voluntad de las partes negociadoras, sino por la sola comunicación del inicio de una fase de negociación, a pesar de que ésta no considere a la totalidad de los acreedores ni sea necesario acreditar que el deudor efectivamente se encuentra en una situación de insolvencia ${ }^{45}$.

${ }^{40}$ Véase: Valpuesta Gastaminza, Eduardo, Los acuerdos de refinanciación en el proyecto de reforma de la Ley Concursal, en Revista de derecho Concursal y Paraconcursal, 15 (2011), p. 159.

${ }^{41}$ Cuestión que se desprende del contenido típico del acuerdo de refinanciación, que exigía la ampliación significativa del crédito disponible o la modificación de sus obligaciones, respondiendo un plan de viabilidad que permitiese la continuidad de la actividad del deudor en el corto y mediano plazo (Disposición adicional $4^{\mathrm{a}}$, párrafo $1^{\circ}$ LC.).

${ }^{42}$ Referencia específica debe ser realizada la sentencia del Juzgado en lo Mercantil número 1 de Madrid, de 21 de mayo de 2007, que rescindió una hipoteca constituida al amparo de un acuerdo de refinanciación, y calificó la mala fe de la actuación del acreedor hipotecario a efectos de subordinar legalmente el crédito de conformidad al artículo 92.6 LC.

${ }^{43}$ Pulgar Esquerra, Juana, Protección de las refinanciaciones, cit. (n. 32), p. 14.

${ }^{44}$ En sentido crítico, se expresan en contra de esta solución BeLtrán SánChez, Emilio - García-Cruces González, José Antonio, cit. (n. 16), pp. 157-158.

${ }^{45}$ López SÁnCHEZ, Javier, cit. (n. 39), pp. 50-51. 
En segundo lugar, se incorpora la figura del "acuerdo de refinanciación homologado", como nuevo instrumento fundado regulatoriamente en el anterior (actual Disposición adicional cuarta LC.). No cabe pensar que el procedimiento de homologación sólo tiene por objeto verificar los extremos propuestos por el legislador para la promoción de su eficacia inter partes, ni el blindaje a las acciones de reintegración ya cubiertas en el modelo de refinanciación ordinario (hoy tratado en el artículo 71.6 LC.), sino "que añade dos particulares efectos que comportan una particular eficacia ultra vires del acuerdo de refinanciación" ${ }^{\prime 4}$. Por una parte, habiendo sido suscrito por acreedores que representen al menos el 55\% del pasivo titularidad de entidades financieras ${ }^{47}$, sus efectos se extienden legalmente a las restantes entidades financieras acreedoras no participantes o disidentes cuyos créditos no estén dotados de garantía real ${ }^{48}$, aunque cabe advertir que la ruptura del efecto relativo se encuentra limitado a las esperas acordadas y no a todo el contenido negocial; y, por otra parte, establece una suspensión del inicio o continuación de cualquier ejecución patrimonial, por un plazo máximo de tres años, a fin de asegurar los resultados de la operación de rescate sin los entorpecimientos que podrían suponer las pérdidas de activos del deudor.

Como puede observarse, estas reglas mantienen la consideración de quienes participan principalmente en esta suerte de acuerdos (acreedores financieros $)^{49}$ y acerca su funcionamiento al "convenio de masa" ${ }^{" 50}, \mathrm{o}$, al

${ }^{46}$ Ibíd., p. 45.

${ }^{47}$ Porcentaje que originalmente era de un $75 \%$, y que fue rebajado por la Ley $\mathrm{N}^{\circ}$ 26/2013, de 27 de diciembre, de cajas de ahorros y fundaciones bancarias.

${ }^{48}$ Para una visión crítica sobre este punto, véase: Olivencia, Manuel, La reforma de la Ley concursal, en Revista de Derecho Mercantil, 285 (2012), pp. 16 y 17.

${ }^{49}$ Sobre el particular, MARTínez Rosado, Javier, Extensión subjetiva de los acuerdos de refinanciación, en Arias VARONA, Francisco Javier (director), Conservación de empresas en crisis. Estudios jurídicos y económicos (Madrid, La Ley, 2013), p. 81, indica: “[...] la homologación de los acuerdos de refinanciación intenta facilitar que los efectos de dichos acuerdos alcancen a un porcentaje mayor de acreedores, se extiendan cuanto más mejor, evitando que las entidades financieras cuyos créditos no estén dotados de garantía real ( $v \cdot g r$., un simple crédito por descubierto) dificulten la continuación de la empresa en tanto, en caso de no suscribir el acuerdo de refinanciación, puedan exigir la satisfacción de sus créditos mermando así las posibilidades de reflotación de la empresa o, en el caso de que ésta sea declarada en concurso con posterioridad, la masa activa". La indudable presencia de los acreedores financieros en toda suerte de negociación extrajudicial de la crisis es puesta de manifiesto por GUGLIELMUCCI, Lino, cit. (n. 9), pp. 317 y 318 , circunstancia que en su momento fundó el denominado "London Approach", como metodología acordada por la banca inglesa para enfrentar concertadamente las situaciones de crisis de sus deudores comunes.

${ }^{50}$ Beltrán Sánchez, Emilio - García-Cruces González, José Antonio, cit. (n. 16), p. 153; y López SÁNCHEZ, Javier, cit. (n. 39), p. 45. 
menos a una solución típicamente concursal ${ }^{51}$. Se advierte aquí un quiebre con la configuración puramente contractual del acuerdo, especialmente por la proyección de sus efectos a terceros no intervinientes, por medio de una técnica, al parecer, paralela a la del principio mayoritario. Pero también debe expresarse que la normativa concursal española nuevamente desecha una estructura colegial para la concreción de una voluntad común, de manera que únicamente cabe reconocer la incidencia de la voluntad individual de los acreedores concurrentes, que, judicialmente homologada, afecta la configuración del crédito y de los derechos de ejecución de los acreedores no concurrentes $^{52}$. Ello, ahora sí, a modo de respuesta al verdadero problema que supone el "holdout" desde la perspectiva del acreedor parásito y el "dilema del prisionero", evitando incluso un hipotético comportamiento abusivo por parte del acreedor minoritario ${ }^{53}$.

Ahora bien, esta ruptura parcial del efecto relativo no se basa directamente en la mayoría exigida, sino especialmente en la calificación jurisprudencial del acuerdo ${ }^{54}$ y a su posibilidad de impugnación ${ }^{55}$. Esta no sólo se refiere al control del cumplimiento de los requisitos formales legalmente previstos, sino que gira especialmente en la valoración de su contenido, apreciando la proporcionalidad de los sacrificios impuestos por el acuerdo a los acreedores no participantes o disidentes ${ }^{56}$. Entonces, la intervención orgánica del acuerdo por medio de la homologación se justifica en una función tutelar de los

${ }^{51}$ Encino Alonso-Muñumer, María, cit. (n. 35), p. 110.

${ }^{52}$ Lo que genera la crítica firmemente planteada por Olivencia, Manuel, cit. (n. 47), p. 19, al señalar que se "aplica el principio de mayoría a los efectos de un contrato, no de un acuerdo de un órgano colegiado, que no existe en ese momento, y en su virtud somete a la minoría a un 'acuerdo' (contrato), que, en principio, no tendría más efectos que los del artículo $1.257 \mathrm{CC}$. entre las partes y sus herederos”.

${ }^{53}$ Pulgar Es $u$ erra, Juana, Protección de las refinanciaciones, cit. (n. 32), p. 21. En cualquier caso, nos parece que la justificación de la ruptura, siquiera parcial, del principio de relatividad de los contratos en la figura del abuso del derecho (contemplado en el artículo 7.2 del CC. español) parece un tanto extrema si se considera que tal conducta abusiva se aprecia como meramente hipotética, esto es, sin necesidad de comprobación de su existencia para la extensión de los efectos. Nos parece que tal quiebre parece justificarse también en la idea del favor debitoris, en términos paralelos a la adopción del principio mayoritario en supuestos de convenios judiciales, y en una solución amparada en la revisión judicial del sacrificio impuesto a los acreedores y a su posibilidad de impugnación por parte de éstos.

${ }^{54}$ Véase: Valpuesta Gastaminza, Eduardo, cit. (n. 40), p. 164.

${ }^{55}$ Pulgar Esquerra, Juana, Protección de las refinanciaciones, cit. (n. 32), pp. 1924.

${ }^{56}$ No obstante, López SÁNCHez, Javier, cit. (n. 39), p. 61, indica: "No se facilita al juez del concurso el parámetro con el que medir la desproporción", concediendo ciertos criterios para comprender su existencia. 
terceros, sin afectar la esencia del modelo privatista parcialmente impuesto por el derecho español. Entonces, no cabe la posibilidad de que el tribunal modifique su contenido, sino que se limite a homologar o no homologar ${ }^{57}$, que, en este contexto, supone extender o no los citados efectos a los acreedores financieros no concurrentes. Entonces, la participación del tribunal no se sustenta en la supervigilancia de intereses generales ajenos a la satisfacción de los acreedores, ni se sobrepone al contenido libremente alcanzado por medio de la concesión de facultades directivas al tribunal, sino que sólo pretende que la fórmula contractual no sea indebidamente utilizada a modo de un contrato en perjuicio de las expectativas de cobro por parte de terceros.

b) El modelo italiano: los planes de saneamiento y los acuerdos de reestructuración. Cabe anotar que los modelos normativos de los acuerdos de refinanciación españoles toman parcialmente como inspiración los "planes de saneamiento" y los "acuerdos de reestructuración" reconocidos en los artículos 67 y 182-bis de la Legge fallimentare italiana (= LF.), incorporados inicialmente en 2005 , reformados finalmente en virtud del Decreto legislativo $\mathrm{N}^{\circ} 83 / 2012^{58}$. Estas fórmulas negociales han sido objeto de continuas modificaciones en los últimos años, especialmente a efectos de incrementar su protección e incentivar su utilización como herramientas de solución de la crisis que ha atravesado gravemente la actividad económica del país ${ }^{59}$. Suponen, en definitiva, dejar en el plano privado la configuración de un mecanismo específico de tratamiento patrimonial y organizativo del deudor, basado principalmente en la negociación de los sacrificios y beneficios obtenidos por los diferentes acreedores, sin mediar la tradicional formulación de la par condicio creditorum $^{60}$. En ambos casos, se omite un tratamiento legislativo del iter negocial del acuerdo, cuestión que se mantiene entregada a la autonomía privada, centrándose en el tratamiento de sus efectos jurídicos, a modo de protección, sea mediante la inmunización de sus actos de ejecución, sea facilitando el propio procedimiento de negociación ${ }^{61}$. Sus configuraciones se presentan razonablemente abiertas en cuanto a sus

${ }^{57}$ López SÁNCHEZ, Javier, cit. (n. 39), pp. 62-63.

${ }^{58}$ Para una revisión de esta materia, véase: INZITIARI, Bruno, Gli accordi di ristturazione ex articulo 182 bis Legge Fallim.: natura, profili funzionali e limiti dell'opposizione degli estranei e dei terzi, en Il Diritto Fallimentare e delle Societá Comerciali, 86 (2012) 1, pp. 13-53.

${ }^{59}$ Para una evolución de la normativa italiana, al menos en lo referente a los acuerdos de reorganización, véase: Guglielmucci, Lino, cit. (n. 9), pp. 353-365.

${ }^{60}$ SANTANGELI, Fabio, Auto ed etero tutela dei creditori nelle soluzioni concordate delle crisi d'impresa (il piano di risanamento, L accordo di ristrutturazione, il concordato preventivo). Le tutele giudiziali dei crediti nelle procedure ante crisi, en Il Diritto Fallimentare e delle Societá Commerciale, 74 (2009) 5, p. 610.

${ }^{61}$ InZITIARI, Bruno, cit. (n. 57), p. 14. 
contenidos, sin encausar el punto a una estrecha figura de recomposición patrimonial, sin perjuicio que su centro y valoración causal se encuentre en la prevención de la insolvencia del deudor y en los mecanismos financieros necesarios para lograr tal propósito.

Los planes de saneamiento, instrumentos valorados en cuanto a su completa desjudicialización, atienden a un único elemento de coordinación con la solución concursal, como es la excepción a su posibilidad de revocación. Se sustenta en el interés expresado por el deudor que, a modo de proteger los negocios que deriven de la ejecución del plan, somete la solución a la consideración de un experto técnico e independiente, que llevará a cabo una calificación de la veracidad de los antecedentes financieros proporcionados y la viabilidad del plan presentado ${ }^{62}$.

Esta solución evidentemente denota ya una completa ausencia de estructuras orgánicas. Por parte de los acreedores, quienes deberán llegar a uno o más acuerdos específicos para la implementación del plan, sin atender a lógicas mayoritarias o participaciones reforzadas. En este caso, la crítica proviene de la escasa tutela que se concede a los acreedores menores (acaso, débiles) en la configuración genética del acuerdo al que, bien pueden no haber sido invitados, o incluso desconocido por la ausencia de medidas de publicidad ${ }^{63}$. La valoración técnica del acuerdo no se fundamenta directamente en la constatación del equilibrio entre los acreedores, partícipes y no partícipes, en el contexto del plan, sino principalmente en su viabilidad como medio de solución de la crisis. Esta cuestión puede justificarse parcialmente en la ausencia de una ruptura de sus efectos relativos, en el sentido que no implicará una alteración de los créditos de los acreedores no partícipes, cuestión que, en esencia, mantiene todos los derechos de los acreedores, sustantivos y procesales, para la protección de su propio crédito, con excepción del ejercicio de las acciones revocatorias. Para tales efectos, el legislador italiano une tal limitación a la valoración positiva de la viabilidad del plan por parte del experto independiente, a fin de eliminar un juicio de reproche de las conductas ejecutivas desplegadas, pero, insistimos, sin conceder medios para una eventual participación por parte de los demás acreedores en cuanto a su valoración y oportunidad.

La carencia de estructuras orgánicas también implica una falta de intervención por parte de un tribunal o entidad administrativa a los que se someta el plan (o los respectivos acuerdos) para su posterior homologación, cuestión que es reemplazada por el juicio técnico del experto (que no alcanza

${ }^{62}$ Di Marzio, Fabrizio, Il diritto negoziale della crisi d'impresa (Milano, Giuffrè, 2011), pp. 117-118.

${ }^{63}$ Santangeli, Fabio, cit. (n. 59), p. 613. 
una calificación orgánica), a modo de análisis previo de su contenido sobre la base de una probabilidad de solución. Sin embargo, este último punto impone que, en caso de fallimento, la verdadera inmunidad del ejercicio de los actos, pagos y garantías enlazadas al plan resultará de un control a posteriori por parte del tribunal ${ }^{64}$, esta vez para asegurarse del cumplimiento de todos los extremos previstos en la norma a efectos de conceder esta suerte de escudo protector, lo que representa un grado de seguridad ciertamente bajo para el deudor y los acreedores partícipes ${ }^{65}$. La revisión judicial, en este caso, será especialmente compleja porque la apertura del "fallimento" denotará un fallo en los pronósticos de viabilidad efectuados por el experto independiente, sea por el contenido específico del plan, o sea por no haber tomado en consideración situaciones exógenas (difícilmente cuantificables) que han impedido al deudor escapar de la insolvencia ${ }^{66}$.

La Legge fallimentare aporta un segundo instrumento de solución -el "acuerdo de reestructuración"- al menos parcialmente negocial, en cuanto se encuentra sujeto al trámite de homologación judicial (artículo 182 bis LF.). Su contenido ha sido entendido como una reorganización de las obligaciones y contratos suscritos por la empresa, considerando conjuntamente la integridad del patrimonio del deudor ${ }^{67}$, bajo el requisito ineludible de asegurar la regular satisfacción de los créditos de los acreedores extraños al acuerdo. En este caso, el modelo se altera de manera de exigir un acuerdo entre el deudor y al menos el sesenta por ciento de los acreedores, adhesiones que, nuevamente, no se articulan sobre la base de principios mayoritarios ni de conformación de una voluntad común, sino únicamente plurilateral ${ }^{68}$, sólo configurando una exigencia de apreciación objetiva de la viabilidad del

${ }^{64}$ Este punto fue debatido por parte de la doctrina y jurisprudencia italiana, especialmente por la configuración de los medios de defensa concedidos a los acreedores para evitar la inmunización revocatoria, hasta el punto de llevar a la derogación del artículo 24.2 LF, sujetando la actividad del tribunal y de los objetores a la ritualidad ordinaria, estimada como mejor garante del derecho constitucional del debido proceso y principio de contradicción. Véase: Constantino, Giorgio, La gestione della crisi d' impresa tra contratto e proceso, en DI MARZIo, Fabrizio - MaCARIO, Francesco (directores), Autonomia negoziale e crisi d' impresa (Milano, Giuffrè, 2010), pp. 216-217.

${ }^{65}$ Capobianco, Ernesto, Gli accordi stragiudiziali per la soluzione della crisi d' impresa. Profili funzionali e strutturali e conseguenze dell'inadempimiento del debitore, en Banca, Borsa, Titoli di Credito, 63 (2010) 3, p. 299.

${ }^{66}$ Santangeli, Fabio., cit. (n. 59), p. 614.

${ }^{67}$ InZiTiaRI, Bruno, cit. (n. 57), p. 16.

${ }^{68}$ Constantino, Giorgio, cit. (n. 63), p. 260 e Inzitiari, Bruno, cit. (n. 57), p. 13, utilizan estas circunstancia para destacar los límites entre el concordato preventivo y el acuerdo de reestructuración. 
mecanismo de reestructuración ${ }^{69}$. Pero en este caso, la protección reforzada concedida por el ordenamiento italiano se orienta en dos sentidos: por una parte, protege la negociación del problema del "holdout", limitando el ejercicio de acciones cautelares o ejecutivas, previo depósito en el tribunal de cierta documentación informativa, de la propuesta específica de acuerdo y la declaración de un experto en términos paralelos a los indicados para el plan de saneamiento ${ }^{70} ; \mathrm{y}$, por otra parte, resguarda igualmente al acuerdo del ejercicio de las acciones revocatorias, pero esta vez fundado en el juicio previo por parte del tribunal acudiendo al trámite de su homologación, lo que permite un nivel de seguridad mayor para los acreedores concurrentes.

Por ello, carente de una estructura propiamente concursal ${ }^{71}$, y a efectos de conciliar la posición de los terceros acreedores, el ordenamiento italiano no pretende un quiebre total de sus efectos relativos ${ }^{72}$, sino una función tutelar de su posición como extraños al acuerdo, a fin de que este pueda ser finalmente homologado ${ }^{73}$. Se reemplaza, entonces, el mecanismo de autotutela que puede conferir un sistema de organización colegial, por una héterotutela conferida a los tribunales sobre el supuesto típico de satisfacción previsto por el ordenamiento jurídico. Ello, mediante la técnica de imponer como requisito fundamental que el acuerdo de reestructuración asegure la integridad del pago a los acreedores extraños, lo que supone que el acuerdo debe contemplar liberaciones de fondos necesarios para estos efectos, consentidas por parte de los acreedores concurrentes ${ }^{74}$.

c) El modelo argentino: los acuerdos preventivos extrajudiciales homologados. En comparación con los modelos anteriores, no puede dudarse que el ordenamiento jurídico argentino ha reaccionado con mayor fuerza para incentivar la celebración de esta clase de "acuerdos preventivos extrajudiciales" ("APEs”), optando por un modelo que puede

${ }^{69}$ Libero Nocera, Ivan, Gli accordi di ristrutturazione come contrato privatistico: il diritto della crisi d'impresa oltre le procedure concorsuali, en Il Diritto Fallimentare e delle Societá Commerciali, 87 (2012) 3 - 4, p. 292; y Terranova, Giuseppe, I nuovi accordi di ristrutturazione: il problema della sottocapitalizacione dell impresa, en Il Diritto Fallimentare e delle Societá Commerciali, 87 (2012) 1, p. 4.

${ }^{70}$ Regulación incorporada por medio del decreto correctivo de 12 de septiembre de 2007, n. 169, a efectos de ofrecer esta clase de paraguas protector a la fase negociadora de esta clase de acuerdos. Sobre el particular, véase: GABRIELLI, Enrico, Accordi di ristrutturazione del debito e tipicità dell operazione económica, en DI MARzIO, Fabrizio . MACARIo, Francesco (directores), Autonomia negoziale e crisi d'impresa (Milano, Giuffrè, 2010), pp. 260-261.

${ }^{71}$ Libero Nocera, Ivan, cit. (n. 68), pp. 392-399.

${ }^{72}$ InZiTIARI, Bruno, cit. (n. 57), p. 15.

${ }^{73}$ Libero Nocera, Ivan, cit. (n. 68), p. 401.

${ }^{74}$ InZITIARI, Bruno, cit. (n. 57), p. 19. 
terminar por romper las bases del efecto relativo de los contratos ${ }^{75}$. Para comprender el punto, debe apreciarse comparativamente la formulación de los "acuerdos preventivos extrajudiciales" por parte de la Ley N ${ }^{\circ}$ 24.522: De concursos y quiebras (= LCQ.), con las modificaciones introducidas a éste por la Ley $\mathrm{N}^{\circ} 25.589$, de 16 de mayo de 2002. Originalmente, el régimen suponía la posibilidad que el deudor y uno o más de sus acreedores celebrasen cualquier clase de acuerdo privado a efectos de resolver la situación de cesación de pagos o un estado de dificultades económicas o financieras de carácter general (artículo 69 LCQ. original), fundado en una absoluta liberalización de sus contenidos (artículo 71 LCQ.). Conforme a estos parámetros, se justificaba que el acuerdo tuviese únicamente efectos relativos, propios de una construcción contractual, suponiendo su eventual revisión en caso de apertura de concurso por medio del ejercicio de las acciones de inoponibilidad. No obstante, y para sortear parcialmente este punto, la Ley de concursos y quiebras admitía la posibilidad de homologación judicial del acuerdo, a efectos de lograr su inmunidad concursal bajo una formulación paralela a la que hoy en día encontramos en la legislación italiana respecto a los acuerdos de reestructuración. Sin embargo, podía resultar difícil construir el fundamento del citado "escudo protector" toda vez que la valoración a ser efectuada por el tribunal no estaba directamente vinculada a una ausencia de perjuicio del pacto privado ante los terceros, ni en la viabilidad de la solución. $\mathrm{Al}$ contrario, la respuesta del ordenamiento argentino no se sustentaba en un examen previo del contenido del acuerdo, sino únicamente en la revisión efectuada por el propio tribunal de los requisitos previstos en el artículo 72 LCQ. y en la ausencia o rechazo de las objeciones presentadas por acreedores que no formasen parte del acuerdo.

Este sistema, escasamente tutelar, se resuelve de modo más extremo a partir de las modificaciones realizadas por la Ley $\mathrm{N}^{\circ} 25.589$. Este nuevo modelo, basado en el esquema antes indicado, protege la negociación e incrementa los efectos del "acuerdo preventivo extrajudicial", en dos sentidos. Por una parte, una vez efectuada la publicidad de la solicitud de homologación, confiere una suspensión de todas las acciones de contenido patrimonial contra el deudor (aunque con ciertas excepciones) (artículo 72 LCQ., modificado por la Ley $\mathrm{N}^{\circ} 26.086$, de 11 de abril de 2006$)^{76}$, y, por la otra, reconduce

${ }^{75}$ La revisión de la normativa argentina también resulta importante por la proximidad del sistema propuesto para la regulación de los APEs con aquel inicialmente contemplado en el mensaje del proyecto de ley que sustituye el régimen concursal vigente por una ley de reorganización y liquidación de empresas y personas y perfecciona el rol de la Superintendencia del ramo (Boletín 8.234-03), que dio origen a la Ley de reorganización y liquidación de empresas y personas, a la que nos referiremos más adelante.

${ }^{76}$ Junyent Bas, Francisco - Germán Macagno, Ariel A., Acuerdo preventivo 
los efectos de la homologación a aquellos previstos en el artículo 56 LCQ., quedando sometido también a las previsiones de las secciones $3^{\mathrm{a}}$, $4^{\mathrm{a}}$ y $5^{\mathrm{a}} \mathrm{del}$ capítulo $5^{\circ}$ del título $2^{\circ}$ de la ley, lo que implica una identificación con los efectos del convenio prejudicial, especialmente en lo referente a la ruptura de sus efectos relativos, y a sus reglas relativas a la novación, nulidad e incumplimiento. Ambos efectos tienen la pretensión de atajar los problemas que resultan de la posibilidad de obstrucción o comportamiento parasitario de los acreedores, pero la reacción normativa puede estimarse como excesiva si se advierte una ausencia de tutela real de la posición de los acreedores no concurrentes. En este sentido, la legislación argentina ha terminado por ofrecer un subtipo concursal ${ }^{77}$, en el sentido que la fase de negociación de los acuerdos queda íntegramente entregada a la lógica contractual ${ }^{78}$, al tiempo que, previa homologación, se obtienen efectos propiamente concursales, aunque no propiamente derivados de la lógica de la aplicación del principio mayoritario y el convenio de masa.

En el modelo argentino, siendo el sistema de homologación una constatación meramente formal, la posibilidad de desequilibrio aparece como un riesgo cierto que el ordenamiento parece no querer atajar, especialmente si se asocia con la conservación de la libertad de contenidos del acuerdo en los términos del artículo $71 \mathrm{LCQ} .{ }^{79}$. Lo anterior da cuenta de la necesidad

extrajudicial con especial referencia a ciertas inconsistencias sistemáticas del nuevo paradigma, en derecho concursal argentino e iberoamericano (Buenos Aires, Ad Hoc, 2003), I, p. 74, quienes dan cuenta que el objetivo de esta modificación legal se basó en la escasa utilización de los APEs, dada la mantención de la posibilidad de agresión al patrimonio del deudor. Ello se agrega a la prevención de DAsso, Ariel, derecho concursal comparado (Buenos Aires, Legis, 2009), I. p. 137, quien sostiene: "No es posible negociar cuando otros traban medidas cautelares que atan al deudor y postergan los derechos de los acreedores a los interlocutores convocados extrajudicialmente".

${ }^{77}$ Véase: Truffat, Daniel, El nuevo acuerdo preventivo extrajudicial (Buenos Aires, Ad Hoc, 2002), p. 26; y Junyent Bas, Francisco - Germán Macagno, Ariel A., cit. (n. 75), pp. 68-71.

${ }^{78}$ Justificación dada, como en otros sistemas, por "la rapidez, la economía en el gasto, y la discreción" de esta fase de negociación [DAsso, Ariel, cit. (n. 75), p. 137].

${ }^{79}$ Véase: Vitolo, Daniel, El nuevo acuerdo preventivo extrajudicial y la violación del derecho de defensa y de debido proceso legal, en derecho concursal argentino e iberoamericano (Buenos Aires, Ad Hoc, 2003), I., p. 15; y Junyent Bas, Francisco - Germán Macagno, Ariel A., cit. (n. 75), p. 72. Un régimen limitativo de la libertad de pacto, estiman estos autores, se justifica en un modelo concursal en el que se produce, por aplicación del principio mayoritario, una imposición a los acreedores minoritarios. Sin embargo, cabe anotar que pensamos que la legitimación de la libertad de pacto también debe sustentarse en la ausencia de asimetrías informativas estructurales entre las partes. El modelo argentino (previo y vigente) no contiene un especial énfasis en esta órbita, de lo que resulta una escasa protección incluso a los acreedores que han estado dispuestos a 
de enfrentar los problemas que acusa una estructura contractual con cierta mesura, en el sentido de no ofrecer un planteamiento alternativo que pueda distorsionar la lógica del ordenamiento privado, y ofrecer, en suma, escasa protección a los terceros no concurrentes. Como señala Dasso: "El nuevo sistema exhibe una superación de los impedimentos operativos existentes para la aplicación en el régimen de la Ley $\mathrm{N}^{\circ} 24.522$, aun cuando desde el punto de vista teórico o sistemático se ha puesto de relieve que en la nueva ley se mezclan elementos heterogéneos incompatibles con la pureza de un ordenamiento extrajudicial adecuado" ${ }^{80}$. A modo de respuesta, y a efectos de proteger la posición de los acreedores no concurrentes, la doctrina y jurisprudencia han dado paso a la aplicación de la teoría del abuso del derecho (recogida expresamente en el artículo 1.071 CC. argentino) en el ámbito concursal, cautelando materias tales como el estándar de la información entregada por el deudor para dar una imagen fiel de su activo y pasivo, la razonabilidad del acuerdo y su impacto en los acreedores no concurrentes, el condicionamiento a la exigibilidad de los créditos, etc., a pesar de haberse dado cumplimiento al régimen de mayorías ${ }^{81}$.

4. El modelo francés de los procedimientos de conciliación: la asistencia técnica para la celebración del acuerdo extrajudicial.

A diferencia de los otros modelos consultados, el procedimiento de conciliation consagrado en el Código de Comercio francés pone especial énfasis en la construcción de un sistema legalmente organizado para facilitar la negociación entre el deudor y sus principales acreedores ${ }^{82}$. Ello puesto que

suscribir el acuerdo preventivo. Lo anterior parece incluso más evidente si se considera el hecho que el ordenamiento sólo exige la presentación de antecedentes por parte del deudor a efectos de lograr su homologación, pero no se incide en la necesidad que los mismos (u otros que den cuenta de su real posición financiera) hayan sido tenidos a la vista por parte de los acreedores al momento de su suscripción. En este sentido, KLEIDERMACHER, Arnoldo, El APE y el regreso a la fuente, en derecho concursal argentino e iberoamericano (Buenos Aires, Ad Hoc, 2003), I, p. 89, concluye: “[...] encontramos serias objeciones con respecto a no exigirse ningún recaudo mínimo para la propuesta y tampoco se establece un procedimiento funcional externo alguno para el control de la información aportada”.

${ }^{80}$ Dasso, Ariel, cit. (n. 75), pp. 139-140.

${ }^{81}$ Véaser: Vítolo, Daniel R., Acuerdos preventivos abusivos o en fraude a la ley (Santa Fe, Rubinzal-Culzoni, 2009), pp. 253-283.

${ }^{82}$ La Ley de 26 de julio de 2005 vino a reemplazar el estatuto jurídico aplicable al modelo de los acuerdos extrajudiciales consagrado previamente en la Ley de 1 de marzo de 1984, bajo la formulación del réglement amiable, que, a su vez había sido modificada por la Ley de 10 de junio de 1994 a efectos de incrementar las facultades del tribunal, especialmente en lo que se refiere a la suspensión de las ejecuciones individuales y la homologación del acuerdo concluido. Para un análisis de este mecanismo previo, sobre 
la legislación francesa, en el contexto de las medidas ofrecidas para la prevención de la insolvencia, ofrece un mecanismo judicialmente tutelado para que las partes puedan llegar a acuerdos dirigidos a la conservación de la empresa, al término de la crisis económica y a la mantención del empleo. Se trasunta en ello una impronta que, si bien atiende a los intereses de cobro por parte de los acreedores, establece una clara prioridad por facilitar herramientas dirigidas a las finalidades conservativas del derecho concursal. En cualquier caso, la intervención del tribunal no hace decaer el carácter contractual del acuerdo $^{83}$, y se inscribe principalmente en la constatación del presupuesto de hecho que da lugar a la factibilidad del procedimiento, en la disminución de asimetrías informativas y en un examen menor (constatación) o mayor (homologación) del acuerdo para consagrar su estatuto jurídico aplicable.

El presupuesto objetivo del procedimiento de "conciliation" se encuentra en la existencia de dificultades jurídicas, económicas o financieras, actuales o previsibles, e incluso en situaciones en que el deudor ya se encuentre en cesación de sus pagos, siempre que ésta no supere el plazo de cuarenta y cinco días. Por medio de tal configuración legal, queda claro que el mecanismo no se contenta únicamente con ser un modelo de prevención de la insolvencia, sino también un mecanismo de solución una vez ésta haya quedado en evidencia, lo que, por medio de una interpretación general del citado presupuesto objetivo, implica la mayor amplitud posible al ejercicio de la autonomía privada ${ }^{84}$. Pero esta coincidencia de presupuestos objetivos presenta también interés en relación a la protección de la negociación enmarcada en el ámbito de la conciliación, puesto que el artículo L. 631-1, dispone que no se entenderá que el deudor se encuentra en un supuesto de cesación de pagos en la medida que compruebe que las reservas de crédito o las moratorias que disfruta de parte de sus acreedores le permitan hacer frente a sus pasivos corrientes con sus activos disponibles. En este sentido, si bien se impide indirectamente la posibilidad de obstrucción por parte de los acreedores, siempre que la ausencia de cesación de pagos sea así declarada a petición de un acreedor, o del Ministerio Público, o de oficio por el tribunal (artículo L. 640-5), la doctrina ha puesto de manifiesto que tal normativa

el cual toma su base el procedimiento de conciliación vigente, véase: RIPERT Georges - Roвlot, René, Droit commercial (17 edición actualizada por Philippe Delebecque y Michel Germain, Paris, Librairie Générale de Droit et de Jurisprudence, 2004), II, pp. 847-854.

${ }^{83}$ Jacluemont, André, Droit des entreprises en difficulté (París, LexisNexis - Litec, 2009), p.50.

${ }^{84}$ Sobre las dificultades que ofrece esta ampliación, especialmente en relación a la determinación de la fecha de cesación de pagos, véase: Jaceuemont, André, cit. (n. 82), p.50. 
puede dar lugar a dudas porque no marca el momento en el cual terminará la restricción para la apertura del procedimiento concursal, especialmente si la negociación no llega a buen puerto ${ }^{85}$.

Procedimentalmente, el trámite se inicia con la presentación efectuada por el deudor al presidente del tribunal de comercio o al presidente del tribunal de "grande instance", según el tipo de deudor que se trate. La solicitud de inicio del procedimiento debe ser acompañada con la información que dé cuenta de la situación económica, social y financiera de la empresa y de sus medios de financiamiento (artículo L. 611-6), adjuntando asimismo el listado de sus principales acreedores, la existencia de garantías, la composición de su pasivo y su principal información contable. Se trata éste de un mecanismo de tutela para los acreedores que participarán en el proceso negociador, y una forma de asegurar que el conciliador podrá mediar sobre la base de datos seguros, en la medida que el tribunal debe revisar la suficiencia de la información otorgada, permitiéndosele incluso, una vez nombrado el conciliador, designar a un experto cuya función es la preparación de un informe complementario respecto a la situación del deudor en caso que estime que los datos suministrados por éste han sido insuficientes. La trascendencia dada al acceso a la información también justifica el hecho que el tribunal puede obtener reportes de parte de los comisarios de cuentas, los miembros y representantes del personal, de las administraciones públicas, los organismos de seguridad social, etc. (artículo L. 611-2), y oficiar a toda clase de establecimientos financieros, para la entrega por parte de ellos de información exacta sobre la posición económica y financiera del deudor en particular (artículo L. 611-6) ${ }^{86}$.

Configurados los presupuestos subjetivos y objetivos ${ }^{87}$, el tribunal procederá al nombramiento del conciliador, que generalmente desempeñará sus

${ }^{85}$ Macorig-Venier, Francine, Entreprises en difficulté. Prévention et réglement amiable, en Revue Trimestrielle de Droit Commercial et de Droit Economique, 2 (2009), pp. 439-440.

${ }^{86}$ JacQuemont, André, cit. (n. 82), pp. 56-57. En cualquier caso, el conciliador no cuenta con poderes directos para el acceso a información del deudor, por lo que, en caso de deficiencias, debe poner éstas en conocimiento del tribunal (artículo L. 611-7, inciso cuarto) para que sea éste quien solicite información adicional. Ello se enmarca asimismo en el carácter confidencial de la labor desempeñada por el conciliador (artículo L. 611-15), que forma parte de la esencia del mecanismo de solución previo a la producción de sus efectos por medio de la eventual homologación del tribunal.

${ }^{87}$ En este punto, el tribunal debe efectuar un examen de fondo de los antecedentes entregados por el deudor o recabados a su iniciativa, de manera que no se logre que por intermedio del procedimiento de conciliación (y, en especial, considerando los efectos que la ley asigna al mismo) se modifiquen o incluso mejoren los términos contractuales en situaciones ajenas a una crisis patrimonial actual o inminente. 
funciones por un plazo de cuatro meses (sujeto, sin embargo, a posibilidades de prórroga, especialmente en caso que se desee obtener la homologación judicial del acuerdo). El objetivo del procedimiento se describe claramente al establecer la función asignada al conciliador en el artículo L. 611-7, al disponer que esta consiste en favorecer la conclusión de un acuerdo entre el deudor y sus principales acreedores, y, de ser aplicable, sus co-contratantes habituales, acuerdo que debe tener por finalidad poner fin a las dificultades de la empresa, y cuyas propuestas deben estar enfocadas en su salvamento, la mantención de la actividad y la conservación del empleo ${ }^{88}$. Los términos empleados por la legislación francesa parecen dar amplitud de contenido suficiente al conciliador para poder efectuar cualquier clase de propuestas de acuerdo, sólo estableciendo limitaciones para la protección de un cierto grupo de acreedores, como los que resultan de relaciones de carácter laboral y previsional (artículo L. 611-7), pero debe tenerse en cuenta que en el sistema francés, la autonomía privada está subordinada a un modelo de corte conservativo, lo que tendrá especial importancia al revisar la intervención del tribunal al tiempo de constatar u homologar el acuerdo.

Ahora bien, alcanzado el acuerdo, éste debe ser presentado ante el órgano jurisdiccional para que alcance fuerza ejecutiva (artículo L. 611-8). Esta alternativa de un acuerdo simplemente constatado por el tribunal alcanza a una revisión de contenidos menor que la que ofrece la homologación judicial, pero que puede resultar igualmente compleja. Ésta se refiere a la verificación de que el deudor no se encuentra actualmente en una situación de cesación de pagos, que ameritaría el pronto inicio de una solución concursal, o que, de existir, ha sido convenientemente resuelta por la aplicación del propio acuerdo. En este punto, si bien el sistema francés resuelve por mantener el esquema contractual tradicional, especialmente en lo que se refiere a la conservación de sus efectos relativos, advierte que la ejecutividad del acuerdo supone un juicio previo que transforma al tribunal en un órgano de carácter técnico-financiero, que debe sopesar la viabilidad del mismo. En esta alternativa se aprecia como el derecho francés sigue prestando atención a la finalidad conservativa del derecho concursal, aun cuando ello implique restringir los efectos de la autonomía privada.

Por su parte, el mismo artículo L. 611-8 agrega la posibilidad de que

${ }^{88} \mathrm{La}$ función del conciliador debe entenderse en el contexto de una mediación, de manera que no se le asignan poderes de decisión, los cuales permanecen entregados al deudor en el contexto de la gestión de sus negocios. De tal modo, las negociaciones con los principales acreedores del deudor nunca podrán ser directas, sino que siempre debe contar con el consentimiento previo del deudor, convenciéndolo asimismo de las ventajas del plan ideado para el rescate de la empresa y sus negocios. Véase: JACQUEMONT, André, cit. (n. 82), p. 56. 
el deudor solicite al tribunal la homologación del acuerdo ya alcanzado. En este caso, el tribunal sí debe proceder, adicionalmente, a un examen de fondo del acuerdo presentado a su conocimiento, con especial atención a los siguientes aspectos: $i$ ) que el deudor no se encuentre en cesación de pagos, o que ésta ha sido resuelta por el acuerdo, haciendo aplicables las prevenciones efectuadas en el párrafo inmediatamente anterior; ii) que los términos del acuerdo son de tal naturaleza que permitan asegurar la continuidad de la actividad de la empresa; y iii) que el acuerdo no importa un atentado en contra de los derechos de los acreedores no concurrentes. Para tales efectos, el tribunal no decide únicamente con los antecedentes presentados, sino que debe resolver previa audiencia del deudor, de los acreedores partícipes, de los representantes del comité de empresas, e incluso de delegados del personal, el conciliador y el ministerio público (artículo L. 611-9). Lo anterior da cuenta de la complejidad de la resolución a ser adoptada por el tribunal, que debe equilibrar los designios alcanzados por las partes con otros intereses que el legislador desea cautelar, como son el equilibrio económico que resulta de la continuidad de la empresa y la estabilidad de los puestos de trabajo.

Pero debe reseñarse que la homologación del acuerdo no incide en la ruptura de sus efectos relativos, sino en la modulación de sus efectos reflejos. Aunque especialmente respecto a los acreedores no signatarios, siempre cabrá la petición efectuada por el deudor para que el tribunal efectúe una revisión judicial de los términos del crédito conforme a las normas generales de los artículos 1.244-1 a 1.244-3 CC. francés, que permiten al tribunal el establecimiento de prórrogas por hasta dos años, la reducción de la tasa de interés o la alteración de las reglas de imputación del pago para reducir el capital adeudado, suspendiendo asimismo todos los procedimientos de ejecución y los aumentos de intereses o multas pactados. En razón de lo anterior, la protección dada a los acuerdos homologados se refiere particularmente a la consagración de su inmunidad revocatoria ${ }^{89} \mathrm{y}$ de un privilegio a los créditos resultantes de nuevos aportes en tesorería ("argent frais") o del otorgamiento de bienes o de la prestación de servicios, en todo caso, destinados a asegurar la continuidad de la actividad de la empresa con posterioridad a la apertura del procedimiento de conciliación (artículo L. 611-11). Ambas consecuencias son las que justifican la publicidad del acuerdo ${ }^{90}$, su posibilidad de impug-

${ }^{89}$ Conclusión a la que se arriba considerando que, salvo el caso de fraude, el tribunal no puede fijar una fecha de cesación de pagos anterior a la sentencia de homologación del acuerdo amistoso (artículo L. 631-8).

${ }^{90}$ Martin-Serf, Arlette - Vallens, Jean-Luc, Les effets pervers de la loi de sauvegarde des entreprises, en Revue Trimestrielle de Droit Commercial et de Droit Economique, 3 (2007), pp. 605 y 606. Pulgar, Juana, Preconcursalidad, cit. (n. 22), pp. 9193, advierte, en este sentido, que uno de los puntos cruciales en la comprensión de la 
nación (incluso por parte del Ministerio Público) y la mayor amplitud del juicio homologatorio, por cuanto es en este contexto en el que el tribunal debe sopesar tanto la viabilidad del acuerdo, como la inexistencia de un atentado contra los derechos de los acreedores no signatarios. Pero puede observarse también que ambas consecuencias atienden a la desactivación del problema del acreedor parásito, en tanto los efectos positivos del acuerdo deben ser asumidos por éste, sea limitando su posibilidad de revocación o soportando el costo que implica la mejora de la posición de los créditos resultantes de los nuevos fondos aportados al deudor en la escala de prelación de créditos.

\section{El ACUERDO EXTRAJUdICIAL EN EL DERECHO CHILENO}

En nuestro sistema jurídico, la posibilidad de un acuerdo extrajudicial se encontraba expresamente recogida en el artículo 169 del libro IV CCom. ${ }^{11}$. Esta normativa fue fruto de las reformas introducidas por la Ley $\mathrm{N}^{\circ} 20.073$, optando por su "total liberalización"92, particularmente al ser comparada con el "convenio extrajudicial" tratado en la antigua Ley $\mathrm{N}^{\circ} 18.175^{93}$. Sin embargo, focalizados en el punto que nos interesa, la regulación se abstraía de cualquier tratamiento de la forma en que los interesados lograban alcanzar el citado acuerdo, centrándose principalmente en la libertad de contenido y en sus efectos relativos. De lo anteriormente indicado, no cabe duda que este modelo inscribía el acuerdo extrajudicial en una categoría contractual, particularizada por su finalidad de resolver los conflictos derivados de la in-

solución francesa gira en torno a la idea de la confidencialidad del acuerdo constatado, y la publicidad del acuerdo homologado, haciendo necesaria tal publicidad precisamente por los efectos reflejos del acuerdo en la posición de los acreedores no signatarios.

${ }^{91} \mathrm{El}$ artículo primero transitorio de la Ley $\mathrm{N}^{\circ} 20.720$ dispone que el citado régimen jurídico seguirá vigente durante todo el periodo de vacancia (nueve meses contados desde su publicación).

${ }^{92}$ Sandoval, Ricardo, Derecho comercial. La insolvencia de la empresa. Derecho concursal: Quiebras, convenios y cesiones de bienes (Santiago de Chile, Editorial Jurídica de Chile, 2007), IV, p. 180.

${ }^{93}$ Cuestión que, según Contreras Strauch, Osvaldo, Insolvencia y quiebra (Santiago, Editorial Jurídica de Chile, 2010), p. 315, denota que "el legislador, con realismo, no cifra muchas expectativas en ellos [...]”. Creemos, al contrario, que el legislador esperaba ofrecer un mecanismo de solución lo suficientemente libre y amplio para albergar diversas fórmulas de autocomposición extrajudicial, aligerándolo de todas las exigencias que habían trabado la operatividad de los convenios extrajudiciales de la legislación anterior. Aunque debemos concordar con Contreras que el resultado no ha podido ser próspero por las dificultades que apuntaremos a continuación. 
solvencia del deudor ${ }^{94}$. Ello hacía aplicable todas las consideraciones generales referidas en la sección segunda del presente trabajo ${ }^{95}$.

De la referencia anteriormente efectuada a los "acuerdos preventivos extrajudiciales", recogidos en la legislación argentina, parece evidente que ha sido éste el modelo tomado en consideración por el legislador chileno para la construcción del acuerdo de reorganización extrajudicial o simplificado. Las notas adicionales añadidas por la Ley de reorganización y liquidación de empresas y personas responden a adecuaciones al sistema concursal global establecido por dicha normativa y por ofrecer algunas soluciones a los problemas que había constatado la doctrina argentina.

Como premisa inicial, cabe tener presente la regulación bifrontal que ofrece el citado mecanismo. El artículo 102 LRLEP. advierte la distinción de dos momentos: el primero, íntegramente negocial, supone que la empresa deudora ha celebrado un acuerdo con sus acreedores, momento que se ciñe totalmente a los paradigmas contractuales antes esbozados; $\mathrm{y}$, el segundo, de carácter eventual, que pasa por la pretensión del deudor de otorgar efectos concursales al contenido del acuerdo por medio de su consecuente aprobación judicial.

Respecto a la etapa negocial, la Ley de reorganización y liquidación de empresas y personas no dispone reglas que traten sobre la fase formativa del acuerdo, de manera que no se pretenden resolver los problemas de asimetría informativa que experimentan las partes ni se regula un íter contractual especial, consolidado sobre la base de reuniones asamblearias, principios mayoritarios o voluntades colegiales. En suma, en esta etapa son absolutamente replicables las observaciones dadas en razón de la formulación contractual de los acuerdos extrajudiciales, y, especialmente, de la regulación antes dispuesta en el artículo 169 del libro IV CCom. Así, esta estructura significará el esfuerzo a realizar por parte del deudor para conseguir las voluntades favorables de un número de acreedores que le permita llevar a efectos el plan de reorganización, que, para efectos de una potencial homologación, deberá ser suscrito por dos o más acreedores que representen tres cuartas partes de su pasivo (artículo 109 LRLEP.). De este modo, no se evitan los riesgos que

${ }^{94}$ Puga Vial, Juan Esteban, Derecho concursal. El convenio de acreedores (Santiago de Chile, Editorial Jurídica de Chile, 2006), pp. 428-431; y Sandoval, Ricardo, cit. (n. 91), p. 180.

${ }^{95}$ Por ejemplo, Román Rodríguez, Juan Pablo, cit. (n. 16), p. 414 anota: “[...] tal libertad contractual y autonomía de la voluntad se encuentran seriamente limitadas por el sistema de inoponibilidades [...]. Tales limitaciones no impiden una franca y leal negociación, sino que actúan como factores preventivos y presenciales para impedir que se abuse de la libertad contractual y de la autonomía de la voluntad de que gozan las partes al llevar a efecto un acuerdo extrajudicial". 
impone el comportamiento estratégico de los acreedores, quienes mantienen la posibilidad de hacer valer las técnicas obstructivas, aunque reducidos en el sentido que la legislación actualmente vigente ha eliminado el deber del deudor de instar por la pronta apertura del concurso. El punto sólo es retomado una vez presentada la solicitud de aprobación judicial del acuerdo ya suscrito, momento en que el tribunal dispondrá la prohibición de solicitar la liquidación forzosa del deudor y de iniciar en su contra juicios ejecutivos, ejecuciones de cualquier clase o restitución en los juicios de arrendamiento, con las excepciones previstas en el artículo 108 letra a) LRLEP., ello conjuntamente la suspensión de la tramitación de los procedimientos ya iniciados.

Concluida esta fase negocial mediante la suscripción del acuerdo, sus efectos se circunscribirán únicamente a quienes han participado favorablemente en el mismo. Situándose aún en una categoría contractual, regirá en plenitud el efecto relativo, pudiendo dar lugar al comportamiento parasitario de los acreedores ajenos al mismo. Debemos aclarar que el procedimiento de aprobación judicial debe entenderse completamente ajeno a su eficacia jurídica, aunque no vemos inconvenientes para que las partes que hayan suscrito el acuerdo alteren tales consecuencias mediante la incorporación de condiciones, sean suspensivas o resolutorias, asociando la producción de sus efectos a la efectiva aprobación judicial del acuerdo.

Ya en esta etapa eventual, cabe reforzar la idea que el quiebre de los efectos relativos del contrato sólo se logrará a partir de la resolución homologatoria por parte del tribunal. A diferencia de los acuerdos de reorganización judicial, el modelo general del acuerdo simplificado no permite entender que estamos frente a la conformación de una voluntad colectiva. La suscripción del acuerdo por parte de un cierto número de acreedores se presenta como un requisito de procedencia para la aprobación judicial, dado que en caso alguno debe estimarse que las declaraciones de voluntad contenidas en el acuerdo simplificado suscrito han sido efectuadas a modo de poner en la práctica la lógica del principio mayoritario, que siempre será funcional a la consagración de modelos en los que se articula una organización de tipo colegial.

Sin embargo, debemos señalar que, al igual que lo que ocurre con los "acuerdos preventivos extrajudiciales" argentinos, la homologación no se sustenta en una forma de protección de los acreedores (concurrentes o no al acuerdo simplificado) en razón de una calificación sustantiva de sus términos, y en caso alguno gira en torno a la idea de revisar su viabilidad o razonabilidad, como ocurre en aquellos esquemas que requieren de la consagración del tribunal como un órgano técnico para revisar las bases financieras de su contenido. La aprobación, en suma, no pretende conformarse en una forma de héterotutela que legitime la ruptura de los efectos relativos del acuerdo, simulando la obtención del consentimiento por parte de todos los acreedores 
sobre la base de un juicio de conveniencia o justicia, sino que se incorpora únicamente como un medio de asegurar el cumplimiento de los requisitos formales establecidos en la propia legislación.

Pero cabe preguntarse si tal protección puede resolverse mediante una actividad oficiosa del tribunal, o si sólo procede motivado por las impugnaciones incoadas a solicitud de parte en virtud de las legitimaciones y causales restringidas cubiertas en el artículo 111 LRLEP. Al respecto, creemos que nuestro ordenamiento ha corregido el inconveniente que ofrece el modelo argentino de los “acuerdos preventivos extrajudiciales" en este punto, por cuanto, hayan existido o no impugnaciones por parte de los acreedores en los términos del citado artículo 111, el artículo 112 LRLEP. permite una actuación oficiosa, en tanto la homologación también se efectuará por el tribunal "previa verificación del cumplimiento de los requisitos legales". Si bien ello no ofrece un mecanismo completo de tutela a los acreedores, lo que resulta coherente con la formulación privatista de nuestro sistema concursal, al menos pretende que el otorgamiento de efectos concursales al acuerdo homologado se encuentre en plena concordancia con la ritualidad procesal y los requisitos básicos dispuestos en nuestro ordenamiento para tales efectos.

El procedimiento de homologación se inicia por la solicitud del deudor ante el tribunal que hubiere sido competente para conocer de un procedimiento concursal de reorganización (esto es, el competente conforme a su domicilio (artículos 3 y 54 LRLEP.), sucesivo al perfeccionamiento del acuerdo extrajudicial con una parte relevante de sus acreedores. El hecho que esta decisión se entregue únicamente al deudor se compadece con la idea que sólo a éste corresponde la presentación de un acuerdo de reorganización judicial (artículo $57 \mathrm{~N}^{\circ} 4$ LRLEP.), cuestión que se basa en el mejor conocimiento que aquél tiene de su posición financiera, como asimismo de su libertad de manejar sus relaciones jurídicas y de decidir dar o no publicidad al acuerdo, requisito indispensable para la ruptura de los efectos relativos.

El deudor debe presentar, conjuntamente al instrumento en el que consta el acuerdo, los antecedentes singularizados en el artículo 56 LRLEP., acompañado por un listado de los juicios y procesos administrativos contra el deudor que tengan efectos patrimoniales y un informe de un veedor con un contenido paralelo al señalado en el artículo $57 \mathrm{~N}^{\circ} 8$ LRLEP., relativo a la información presentada por el deudor y la viabilidad y conveniencia del acuerdo. Respecto a estos antecedentes, cabe advertir que su utilidad puede ser cuestionada en razón que ella aparece como posterior al término de la fase de negociación. De esta manera, los antecedentes reseñados en el artículo 56 LRLEP., como los agregados en el artículo 107 LRLEP., no se encuentran dirigidos a los acreedores que ya lo han suscrito, de manera que no pueden asociarse con fórmulas para resolver problemas de asimetría informativa en el 
iter negocial. Así, tampoco parecen particularmente dirigidos a los acreedores que no han formado parte del acuerdo, puesto que no pueden utilizar la información así acompañada, especialmente en lo que se refiere a la referida viabilidad y conveniencia, como una justificación para su impugnación, sino que, en los términos del artículo 111 LRLEP., sólo en lo que atañe a la identificación del pasivo para la consecución de la adhesión necesaria para que tenga lugar la homologación.

Dada la necesidad de encontrar sentido a estas normas, creemos necesario comprender que ellos deben ser necesariamente comprendidos como funcionales al procedimiento de aprobación judicial. Respecto a la información relativa a los bienes, garantías y juicios del deudor, estos deben asociarse a los efectos procesales de la presentación de la solicitud, en cuanto el tribunal deberá disponer la prohibición de solicitar la liquidación forzosa del deudor y de iniciarse en su contra juicios ejecutivos, ejecuciones de cualquier clase o restitución en los juicios de arrendamiento, suspendiéndose, además, la tramitación de tales procedimientos, en caso de haberse iniciado (artículo 108 LRLEP.). Estas consecuencias no deben entenderse como formas de protección de la negociación (como en los sistemas italiano y español), sino como una forma de dar preeminencia a la solución extrajudicial, sin obstrucciones, hasta el momento de su eventual aprobación. Sin ella, el solo hecho de dar publicidad al acuerdo (necesario para dar curso al procedimiento de homologación conforme al artículo 110 LRLEP.) consagraría un desajuste entre la pretensión de reorganización por parte de un número considerable de los acreedores del deudor, con la posibilidad de obstrucción de los demás acreedores, al menos aparentemente minoritarios, a efectos de dar inicio a un procedimiento de liquidación o de disgregación del patrimonio del deudor por medio de ejecuciones singulares.

Por su parte, la referencia al certificado de auditor externo y a la contabilidad y balance del deudor, permitirán la identificación de sus acreedores, tanto para la designación del veedor por parte del deudor y sus dos principales acreedores (artículo 107 LRLEP.), como para la certificación del “quórum” de acreedores necesario para su aprobación definitiva (artículo 109 LRLEP.) ${ }^{96}$. Este último punto tiene una relevancia crucial puesto que, por una parte, la negociación y suscripción, y, por la otra, el procedimiento de aprobación de los acuerdos de reorganización extrajudiciales, no contienen reglas para la determinación del pasivo paralelas a las que se ofrecen en los símiles judiciales del acuerdo, sobre la base del reconocimiento de créditos por medio de su

${ }^{96}$ La referencia al "quórum" expresada en el título del artículo 109 LRLEP. nos parece imprecisa. No hablamos de mayorías, propias de un sistema de votación, sino de un número mínimo de acreedores que deben haber suscrito el acuerdo simplificado para efectos de su homologación. 
verificación e impugnación, de manera que los mecanismos de resguardo se basan únicamente en estas certificaciones y documentación (artículo 56 LRLEP.), en la calificación efectuada por el veedor en su informe respecto a la determinación de los créditos y preferencias (artículo 107 LRLEP.) y en la posibilidad de impugnación sustentada en una errónea conformación del pasivo (artículo 111 LRLEP.).

Lo que, en principio, no parece tener suficiente justificación se refiere precisamente al informe del veedor solicitado en razón del referido artículo 107 LRLEP., al menos en lo que se refiere a la susceptibilidad de cumplimiento del acuerdo y el monto probable de recuperación en un hipotético escenario de liquidación. Como hemos indicado, a diferencia de otros sistemas jurídicos, no se establece un juicio de fondo para sustentar la decisión por parte del tribunal para aceptar o rechazar la homologación del acuerdo. En razón de nuestra marcada orientación privatista, el tribunal no tiene facultades de intervención en relación a su contenido u oportunidad, como tampoco de dirección en términos de impulsar u ordenar su modificación a fines de asegurar la eficiencia o justicia de la solución, pero sí para asegurarse que, de contar con dicha información, se mantienen las expresiones de voluntad por parte de los acreedores concurrentes. Por ello, la existencia de un informe desfavorable puede ser un fuerte indicio para que el tribunal haga valer la posibilidad conferida en el primer inciso del artículo 112 LRLEP., en el sentido de citar a todos los acreedores a quienes pudiese afectar el acuerdo para reafirmar su aceptación ante el tribunal. Se trata ésta de una facultad concedida a los tribunales para actuar en este contexto de manera oficiosa y discrecional, dado que la revisión del acuerdo propiamente tal sólo pasará por la eventual impugnación del mismo presentada por los acuerdos disidentes y aquéllos que demuestren haber sido omitidos de los antecedentes previstos en el artículo 107 LRLEP., basado en idénticas causales de impugnación al acuerdo de reorganización judicial, o sobre la existencia, montos y preferencias de sus créditos (artículo 111 LRLEP.) y en la verificación de los requisitos formales del acuerdo para proceder a su homologación (artículo 112 LRLEP.).

Sin embargo, insistimos en que la principal innovación impulsada por esta regulación se refiere a la ruptura de los efectos relativos del acuerdo, a fin de conceder al acuerdo de reorganización extrajudicial efectos propiamente concursales. Nos parece que en la Ley de reorganización y liquidación de empresasy personas, a partir de la regulación especial referida a su homologación, es indudable que la aplicación de esta segunda fase trasmuta la figura en un mecanismo necesariamente concursal que viene en reemplazar la regulación propia de los acuerdos de reorganización judicial, al menos en lo referente al proceso de negociación y conformación de una voluntad colectiva. En pocas 
palabras, el sistema pretende desjudicializar íntegramente la fase de negociación, tal como ocurre en el modelo norteamericano de los "pre-packaged arrangements", hasta llegar a la eventual fase de aprobación. Iniciado este procedimiento, se replica para este instrumento, especialmente en todo cuanto se refiere a su impugnación (artículo 111 LRLEP.), y, eventualmente, el régimen de nulidad e incumplimiento (artículo 114 LRLEP.).

Ya hemos indicado que tal ruptura no se justifica en la configuración de una lógica mayoritaria ni en un sistema de asambleas, sino que surge como resultado de un proceso judicial y su consecuente resolución homologatoria basado únicamente en expedientes formales. Así, la ausencia de tutelas de fondo resulta consonante con una formulación que ha optado por restringir el ámbito de aplicación del principio autoritario, y en que los resguardos concedidos a los acreedores parecen circunscribirse a la ritualidad procesal y a la exigencia que un alto porcentaje del pasivo haya suscrito el acuerdo simplificado. Pero aún en este sentido cabe albergar dudas sobre la posibilidad que, al igual que en el derecho argentino, los tribunales pudiesen hacer valer el expediente general del "abuso del derecho" a efectos de negar la aprobación judicial del acuerdo. La pregunta resulta válida en tanto nuestro ordenamiento, a diferencia del argentino, no contiene una reglamentación expresa de tal instituto.

Para los efectos de la extensión de los efectos de los acuerdos simplificados, el sistema se sustenta en dos premisas: la publicidad de los términos del acuerdo y de sus documentos fundantes (artículo 110 LRLEP.) y de la resolución judicial que termina por concederles efectos concursales (artículo 112 LRLEP.); lo primero, funcional a la posibilidad de impugnación a los acreedores en razón del artículo 111 LRLEP., y, lo segundo, para asegurar su eficacia concursal en los términos del artículo 113 LRLEP. Por su parte, en la constatación judicial del cumplimiento de los requisitos formales necesarios para lograr la ruptura de la eficacia relativa del acuerdo, y el otorgamiento de esta clase de tutelas en directa referencia a los acreedores minoritarios. Considérese, en estos términos, que la homologación del acuerdo requiere que el acuerdo simplificado haya sido suscrito por dos o más acreedores que representen tres cuartas partes del pasivo del deudor, de manera que el resguardo formal debe comprenderse en tanto encausado a los acreedores que representen el pasivo restante, sin considerar las declaraciones de voluntad a los acreedores que son personas relacionadas al deudor o cesionarios de créditos adquiridos dentro de los treinta días anteriores a la fecha de presentación para obtener la aprobación judicial.

En suma, esta lógica del procedimiento se circunscribe en la necesidad de conciliar el aplacamiento de las estrategias de "holdout" de estos acreedores minoritarios y la correcta tutela de estos últimos. Ello, en primer término, en 
lo que se refiere a evitar el inicio de procedimientos judiciales de liquidación o ejecuciones singulares en el contexto del proceso homologatorio (artículo 108 LRLEP.) y, con posterioridad a la aprobación judicial, en razón de los efectos absolutos del acuerdo del acuerdo simplificado judicialmente aprobado (artículo 113 LRLEP.), en ambos casos con la finalidad de impedir la obstrucción por parte de la minoría. Y, ya en segundo lugar, para evitar los efectos de la eventualidad del comportamiento parasitario de los terceros acreedores, permitiendo la extensión de los efectos del acuerdo, especialmente en lo referente a los sacrificios negociados con los acreedores concurrentes.

\section{CONCLUSIONES}

$1^{\circ}$ Una visión privatista del derecho concursal, basada principalmente en la identificación de los intereses particulares de los acreedores con el interés general de maximizar sus posibilidades de cobro, admitirá que sean éstos los principales actores en la decisión del destino de los bienes y actividades del deudor. En este contexto, la utilización de modelos extrajudiciales se advierte legalmente justificada y económicamente beneficiosa en aquellos casos en los que los costos de transacción sean inferiores a aquellos que ofrece una solución íntegramente concursal.

$2^{\circ}$ No obstante, cabe advertir que una formulación estrictamente contractual del acuerdo extrajudicial puede suponer ciertos fallos de mercado que pongan en peligro su éxito, lo que resultará principalmente de la ausencia de asistencia técnica en el proceso de negociación, agravado por la existencia de asimetrías informativas, y de las dificultades que propone la falta de coordinación con las respuestas concursales favorecidas por el ordenamiento jurídico, dando pie a un comportamiento obstructivo o parasitario de los acreedores no concurrentes.

$3^{\circ}$ Una configuración contractual, como la que ofrece el libro IV CCom., desconoce las deficiencias de esta solución, de manera que la utilización del acuerdo extrajudicial sólo resultaría eficiente en un limitado número de supuestos en los que existe una gran heterogeneidad de los acreedores y una estructura societaria y financiera bastante básica. En los demás casos, este mecanismo no ofrece suficientes garantías para las partes involucradas, sea por la mantención del deber de solicitar la quiebra por parte del deudor calificado del artículo 41 del libro IV CCom., la ausencia de limitaciones a los acreedores para iniciar ejecuciones singulares o para solicitar la apertura del concurso, o la eventualidad de la revocación de los actos de ejecución del acuerdo en el marco de una quiebra posterior.

$4^{\circ}$ En atención a las deficiencias de la estructura contractual, el derecho comparado ha dado cuenta de diversos modelos por los cuales pretenden 
resolverse los problemas antes apuntados, consagrando especialmente reglas de coordinación con las soluciones concursales o estableciendo modelos orgánicos de negociación extrajudicial. Sin embargo, un punto crucial al respecto se refiere al debate sobre la necesidad de dar o no ruptura al efecto relativo de los contratos y al tipo de salvaguardas que pueden ofrecerse a los terceros no concurrentes en caso de optar por una solución afirmativa. Esta cuestión pasa por entender que un modelo contractual no se construye sobre una organización colegial que justifique la aplicación del principio mayoritario, comprendiendo que aquél está destinado a ofrecer garantías a los acreedores minoritarios en el ejercicio de su derecho a voz y voto. La alternativa, si cabe, debe buscarse en el reemplazo de un sistema de autotutela en el marco de la referida estructura colegial, por un sistema de protección judicial (heterónomo) que asegure el respeto a su posición jurídica en términos siquiera similares.

$5^{\circ}$ Sin embargo, la dificultad de conciliar los beneficios de las herramientas concursales y no concursales, y la debida protección de todos los intereses involucrados, da cuenta de la continua necesidad de revisión de esta materia por parte de los ordenamientos jurídicos. El complejo equilibrio se balancea con riesgos ante el alcance de las situaciones de crisis que han motivado las nuevas regulaciones, por lo que sus conclusiones han sido especialmente atendidas para el perfeccionamiento de nuestro ordenamiento, en particular en el marco de la Ley de reorganización y liquidación de empresas y personas. A nuestro juicio, el énfasis debe estar dado por el análisis de la incidencia de las asimetrías informativas involucradas, complementando el deber general de buena fe de las partes en el iter negocial; en el reconocimiento del conflicto de interés ínsito en una orientación privatista del derecho concursal, atajando efectivamente las posibilidades de abuso; y en la revisión de las externalidades positivas y negativas del acuerdo como criterios que guíen la protección legal de los intereses en juego.

\section{BIBLIOGRAFÍA}

Álvarez San José, María, Elpoder de decisión de los acreedores en el concurso (Cizur Menor, Thomson - Civitas, 2005).

Arias VARONA, Francisco Javier, Los acuerdos de refinanciación en el contexto comparado, en Arias Varona, Francisco Javier (director), Conservación de empresas en crisis. Estudios jurídicos y económicos (Madrid, La Ley, 2013).

Beltrán SÁnchez, Emilio, Insolvencia, insolvencia inminente e insolvencia cualificada, en Sarcina, Antonio y García-Cruces, José Antonio (directores), Il trattamento giuridico della crisi d' impresa. Profili di diritto concorsuale italiano e spagnolo a confronto (Bari, Cacucci, 2008).

Beltrán Sánchez, Emilio - García-Cruces González, José Antonio, Acuerdos 
de refinanciación, en BeLtrán Sánchez, Emilio - García-Cruces, José Antonio (directores), Enciclopedia de derecho concursal (Cizur Menor, Thomson Reuters - Aranzadi, 2012).

Betker, Brian L., An Empirical Examination of Prepacked Bankruptcy, en Financial Management, 24 (1995) 1.

Capobianco, Ernesto, Gli accordi stragiudizialiper la soluzione della crisi d' impresa. Profili funzionali e strutturali e conseguenze dell'inadempimiento del debitore, en Banca, Borsa, Titoli di Credito, 63 (2010) 3.

COASE, Ronald, The Problem of Social Cost, en Journal of Law and Economics, 3 (1960).

Collins, Sean - IsaAC, R. Mark, Holdout: Existence, Information, and Contingent Contracting, en The Journal of Law and Economics, 55 (2012) 4.

Constantino, Giorgio, La gestione della crisi d'impresa tra contratto e proceso, en DI Marzio, Fabrizio - Macario, Francesco (directores), Autonomia negoziale e crisi d'impresa (Milano, Giuffrè, 2010).

Contreras Strauch, Osvaldo, Insolvencia y quiebra (Santiago de Chile, Editorial Jurídica de Chile, 2010).

Dasso, Ariel, Derecho concursal comparado (Buenos Aires, Legis, 2009), I.

D'AtTore, Giacomo, Il conflitto d'interesi fra creditori nei concordati, en Giurisprudenza Commerciali, 36 (2009) 6.

DE la Cuesta Rute, José María, El convenio concursal. Comentarios a los artículos 98 a 141 de la Ley concursal (Cizur Menor, Thomson - Aranzadi, 2004).

DE la MAZa Gazmuri, Ínigo, Los limites del deber precontractual de información (Cizur Menor, Civitas - Thomson Reuters, 2010).

Di Marzio, Fabrizio, Il diritto negoziale della crisi d'impresa (Milán, Giuffrè, 2011).

Encino Alonso-Muñumer, María, El plan de viabilidad en el ámbito de los acuerdos de refinanciación, en ARIas VARONA, Francisco Javier (director), Conservación de empresas en crisis. Estudios jurídicos y económicos (Madrid, La Ley, 2013).

Epstein, Richard A., Holdouts, Externalities and the Single Owner: One More Salute to Ronald Coase, en The Journal of Law and Economics, 36 (1993) 1.

FERNÁNDEZ DEL POZO, Luis, El régimen jurídico preconcursal de los "acuerdos de refinanciación” (d.ad. $4^{a}$ LC). Propuesta de reforma legislativa (Madrid, Colegio de Registradores de la Propiedad y Mercantiles de España, 2010).

Ferrari, Franco, La formación del contrato, en Galgano, Francesco (coordinador), Atlas de derecho privado comparado (traducción de Juan Antonio Fernández Campos y Rafael Verdera Server, Madrid, Fundación Cultural del Notariado, 2010).

GABRIELli, Enrico, Accordi di ristrutturazione del debito e tipicità dell operazione económica, en Di Marzio, Fabrizio - MaCARIo, Francesco (directores), Autonomia negoziale e crisi d’impresa (Milano, Giuffrè, 2010).

García-Cruces GonzÁlez, José Antonio - López SÁnCheZ, Javier, La reforma de la Ley concursal. Una primera lectura del Real Decreto - ley 3, 2009 (Cizur Menor, Aranzadi Thomson Reuters, 2009).

Goldenberg Serrano, J. L., Los acuerdos extrajudiciales en la legislación concursal, en Revista de Derecho de la Empresa, 20 (2009).

Vitolo, Daniel, El problema temporal en el inicio de los procedimientos concursales, en Ius et Praxis, 18 (2012) 1.

Vitolo, Daniel, Bases de la privatización del derecho concursal, en Revista Chilena de Derecho Privado, 20 (2013).

Guglielmucci, Lino, Diritto Fallimentare (Turín, G. Giappichelli Editore, 2012). 
GutiéRrez Gilsanz, Andrés, Tutela de los acreedores frente al convenio concursal: Oposición, nulidad y declaración de incumplimiento (Getafe, La Ley, 2009).

JACKSOn, Thomas, The Logic and Limits of Bankruprcy Law (Cambridge, Harvard University Press, 1986).

Jacluemont, André, Droit des entreprises en difficulté(Paris, LexisNexis - Litec, 2009).

Junyent Bas, Francisco-Germán Macagno, Ariel A., Acuerdo preventivo extrajudicial con especial referencia a ciertas inconsistencias sistemáticas del nuevo paradigma, en derecho concursal argentino e iberoamericano (Buenos Aires, Ad Hoc, 2003), I.

ILLESCAS, Rafael, Los acuerdos de refinanciación y reestructuración, en La reforma concursal. III Congreso Español de Derecho de la Insolvencia (Cizur Menor, Civitas - Thomson Reuters, 2011).

INZITIARI, Bruno, Gli accordi di ristturazione ex articulo 182 bis Legge fallim.: natura, profili funzionali e limiti dell'opposizione degli estranei e dei terzi, en Il Diritto Fallimentare e delle Societá Comerciali, 86 (2012) 1.

KLEIDERMACHER, Arnoldo, El APE y el regreso a la fuente, en derecho concursal argentino e iberoamericano (Buenos Aires, Ad Hoc, 2003), I.

Libero Nocera, Ivan, Gli accordi di ristrutturazione come contrato privatistico: il diritto della crisi d' impresa oltre le procedure concorsuali, en Il Diritto Fallimentare e delle Societá Commerciali, 87 (2012) 3-4.

López-Cuñat, Javier Mateo, Adverse Selection Under Ignorance, en Economic Theory, 16 (2000) 2.

López SÁnchez, Javier, El proceso concursal (Cizur Menor, Thomson Reuters Aranzadi, 2012).

López Santa María, Jorge, Los contratos. Parte general (5a edición actualizada por Fabián Elorriaga de Bonis, Santiago, Abeledo Perrot - LegalPublishing, 2010).

McCormack, Gerard, Corporate Rescue Law. An Anglo-American Perspective (Cheltenham, Edward Elgar Publishing, 2008).

Macorig-Venier, Francine, Entreprises en difficulté. Prévention et règlement amiable, en Revue Trimestrielle de Droit Commercial Et De Droit Economique, 2 (2009).

Martin-Serf, Arlette - Vallens, Jean-Luc, Les "effets pervers" de la loi de sauvegarde des entreprises, en Revue Trimestrielle de Droit Commercial et de Droit Economique, 3 (2007),.

Martínez Rosado, Javier, Extensión subjetiva de los acuerdos de refinanciación, en ARIAS VARONA, Francisco Javier (director), Conservación de empresas en crisis. Estudios jurídicos y económicos (Madrid, La Ley, 2013), pp. 67 - 102.

Méndez González, Fernando P., Fundamentación económica del derecho de propiedad privada e ingeniería jurídica del intercambio personal (Cizur Menor, Civitas - Thomson Reuters, 2011).

Núñez Ojeda, Raúl - Carrasco Delgado, Nicolás, La quiebra sin bienes. Una aproximación desde el análisis económico del derecho, en Ius et Praxis, 17 (2011) 1, 176.

Núñez Ojeda, Raúl, Carrasco Delgado, Nicolás, y Ortiz Rojo, Francisco, Visión crítica desde el análisis económico del derecho al sistema de verificación de créditos y realización de activos en la ley de quiebras chilena, en Ius et Praxis 18 (2012) 1.

Olivencia, Manuel, La reforma de la Ley concursal, en Revista de Derecho Mercantil, 285 (2012).

Posner, Richard, Economic Analysis of Law (Boston / Toronto, Little Brown, 1977).

Pulgar Esquerra, Juana, Protección de las refinanciaciones de deuda frente a solicitudes de concurso necesario: sobreseimiento en los pagos y comunicación ex articulo $5.3 \mathrm{LC}$ en el marco del RDL 3/2009, en Revista de derecho Concursal y Paraconcursal, 11 (2009). 
Pulgar EsQuerra, Juana, Acuerdos de refinanciación y "fresh money", en Revista de derecho Concursal y Paraconcursal, 15 (2011).

Pulgar Esquerra, Juana, Preconcursalidad y acuerdos de refinanciación (Madrid, La Ley, 2012).

Puga Vial, Juan Esteban, Derecho concursal. El convenio de acreedores (Santiago de Chile, Editorial Jurídica de Chile, 2006).

Ripert, Georges, Tratado elemental de derecho comercial (traducción de Felipe de Solá Cañizares, Buenos Aires, Tipográfica Editora Argentina, 1954), IV.

Ripert Georges - Roblot, René, Droit commercial (17a edición actualizada por Philippe Delebecque y Michel Germain, Paris, Librairie Générale de Droit et de Jurisprudence, 2004), II.

Roe, Mark J., The Voting Prohibition in Bond Workouts, en The Yale Law Journal, 97 (1987) 2.

Román Rodríguez, Juan Pablo, Instituciones de derecho concursal (Santiago de Chile, Abeledo Perrot - Thomson Reuters, 2011).

Sandoval López, Ricardo, Derecho comercial. La insolvencia de la empresa. Derecho concursal: Quiebras, convenios y cesiones de bienes (Santiago de Chile, Editorial Jurídica de Chile, 2007), IV.

SANTANGELI, Fabio, Auto ed etero tutela dei creditori nelle soluzioni concordate delle crisi d'impresa (il piano di risanamento, Laccordo di ristrutturazione, il concordato preventivo). Le tutele giudiziali dei crediti nelle procedure ante crisi, en Il Diritto Fallimentare e delle Societá Commerciale, 74 (2009) 5.

SatTa, Salvatore, Instituciones de derecho de quiebras (traducción y notas de derecho argentino por Rodolfo O. Fontanarrosa, Buenos Aires, Ediciones Jurídicas EuropaAmérica, 1951).

Schwartz, Alan, Bankruptcy Workouts and Debt Contracts, en Journal of Law and Economics, 36 (1994) 1.

Terranova, Giuseppe, I nuovi accordi di ristrutturazione: il problema della sottocapitalizacione dell impresa, en Il Diritto Fallimentare e delle Societá Commerciali 87 (2012) 1.

Tirado Martí, Ignacio, Reflexiones sobre el concepto de "interés concursal" (Ideas para la construcción de una teoría sobre la finalidad del concurso de acreedores), en Anuario de Derecho Civil,62 (2009) 3.

Truffat, Daniel, El nuevo acuerdo preventivo extrajudicial (Buenos Aires, Ad Hoc, 2002).

Usher, Dan, The Coase Theorem is Tautological, Incoherent or Wrong, en Economic Letters, 61 (1998).

Valpuesta Gastaminza, Eduardo, Los acuerdos de refinanciación en el proyecto de reforma de la Ley Concursal, en Revista de derecho Concursal y Paraconcursal 15 (2011), pp. $155-165$.

Vitolo, Daniel, El nuevo acuerdo preventivo extrajudicial y la violación del derecho de defensa y de debido proceso legal, en derecho concursal argentino e iberoamericano (Buenos Aires, Ad Hoc, 2003), I..

Acuerdos preventivos abusivos o en fraude a la ley (Santa Fe, Rubinzal - Culzoni, 2009).

Warren, Elizabeth, Chapter 11:Reorganizing American Businesses (Nueva York, Wolters Kluwer, Aspen Publishers, 2008). 
